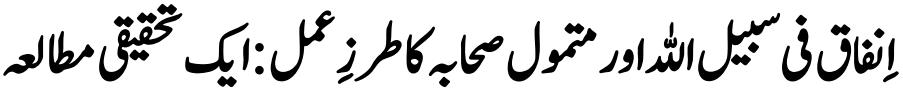

\section{Spending in the Way of Allah and its Practice in the Lives of Richest Companions of the Prophet Muhammad [P.B.U.H]: \\ A Research Study}

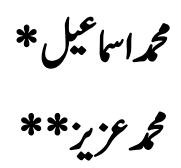

\begin{abstract}
Spending in the way of Allah (Infaq fi Sabilillah) is an important institution of Islam. Allah the Almighty stressed on such kind of spending in many places of the Holy Quran. Moreover, Prophet Muhammad [P.B.U.H] companions always practiced the teaching about such spending through their sayings and actions. In order to investigate about such sort of spending in the lives of richest Companions, an archival research methodology is used, which is a widely used research approach in Islamic studies and Islamic theology. The study reviewed the available prominent and established literature, to investigate the consciousness of richest Prophet Muhammad's Companions [RA] toward Infaq fi Sabilillah. The study concluded that the lives of the Companions are full of scarifications, and both mandatory and voluntary spending in the name of Allah. The total sum of such spending by the top four richest Companions is far greater than the total wealth of present wealthy people globally. After all such huge spending, their wealth increased day after day and never got decreased. This is the Divine law of spending which says that spending in the way of Allah leads to increase in Wealth.
\end{abstract}

Keywords: Islamic Economics, Infaq fi Sabeelillah, Poverty, Alleviation in Islam.

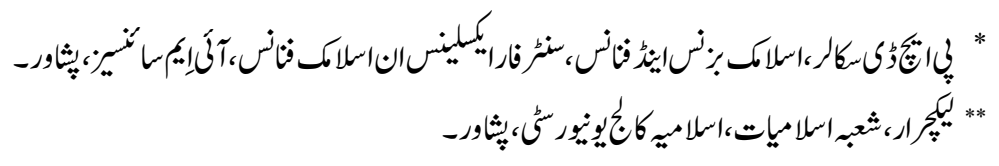




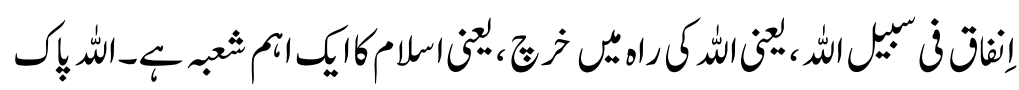

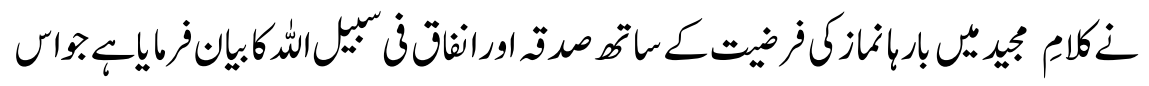

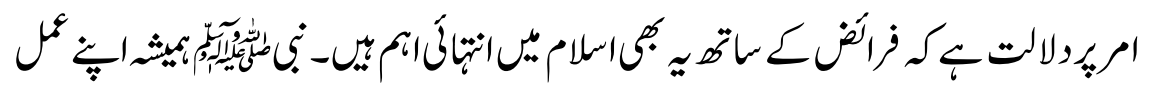

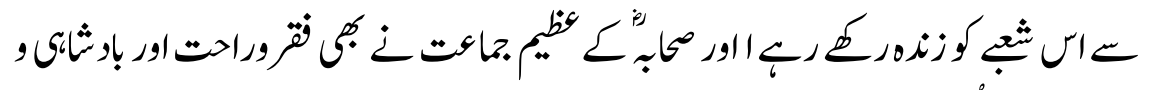

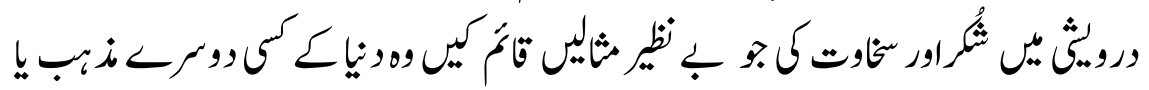

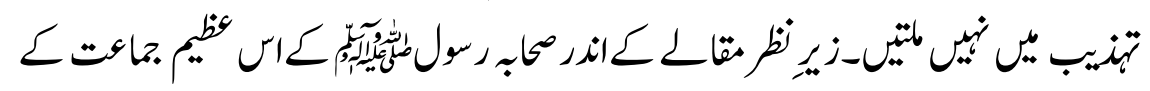

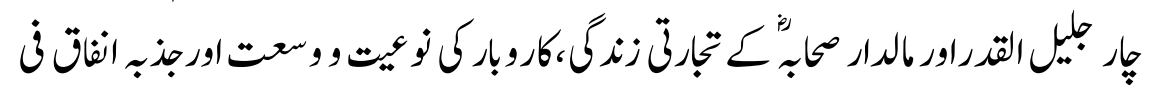

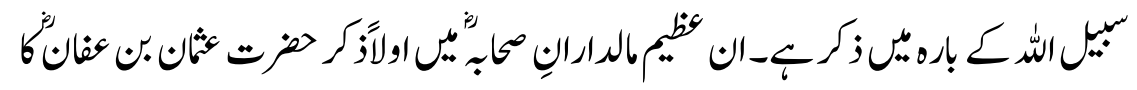

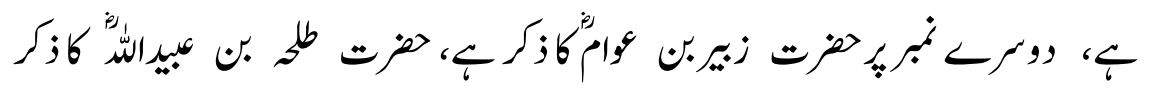

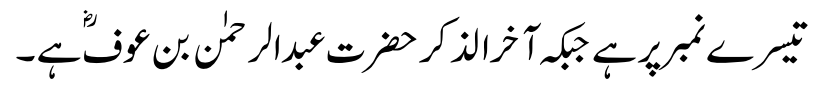

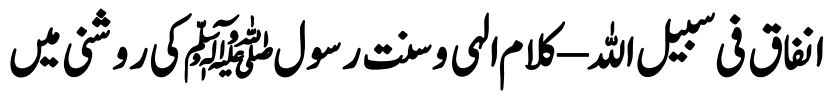

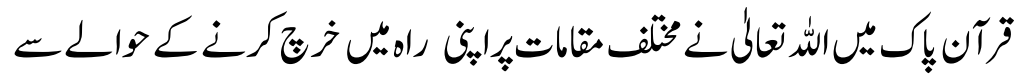

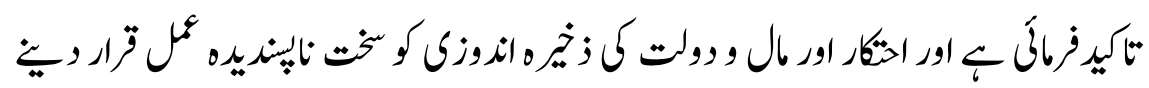

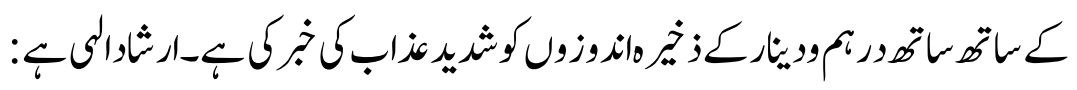

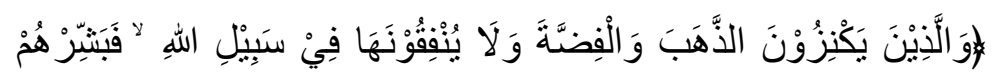

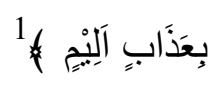

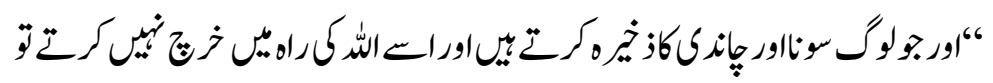

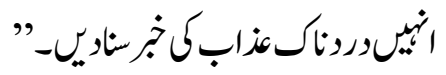

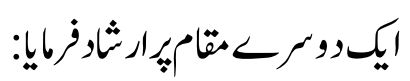

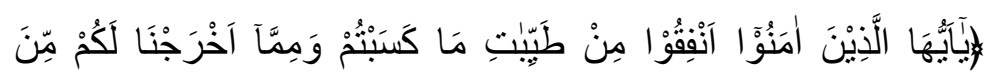

$$
\text { الآَرْضِ }
$$




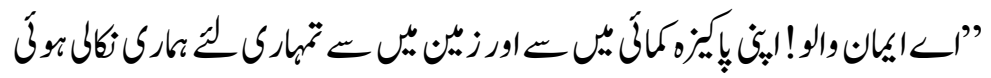

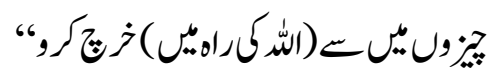

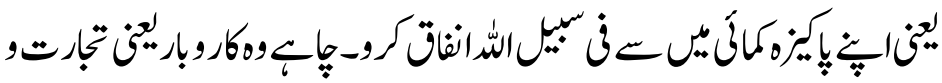

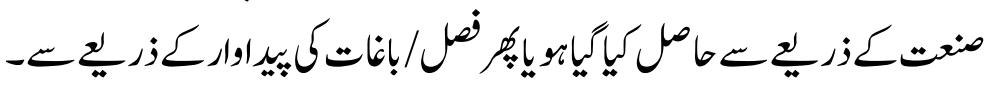

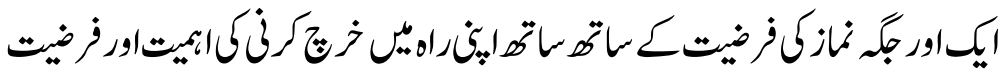

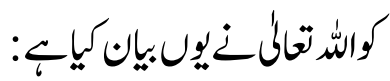

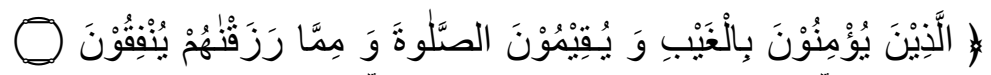

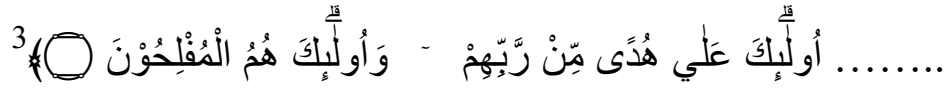

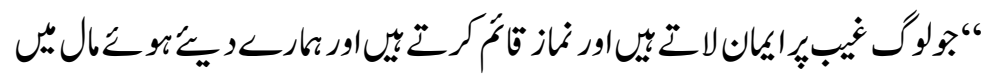

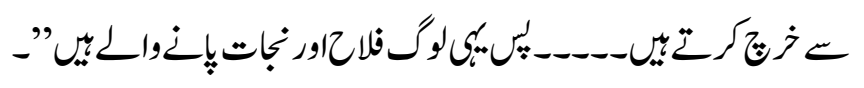

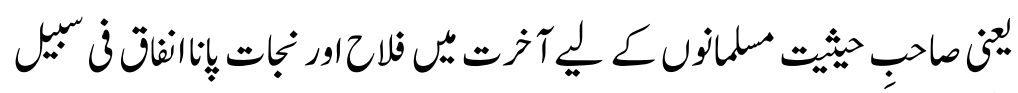

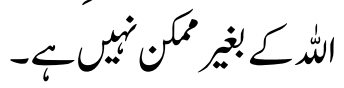

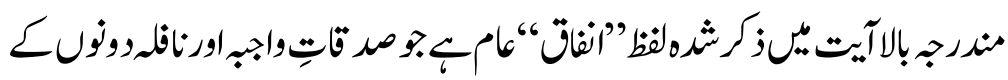

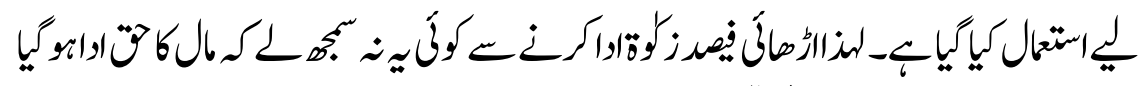

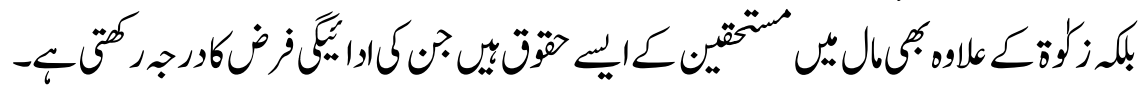

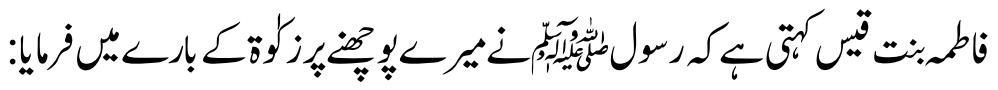

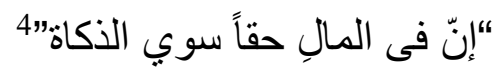

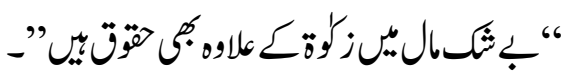

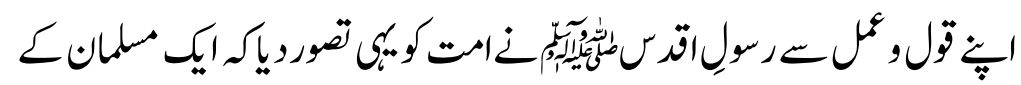

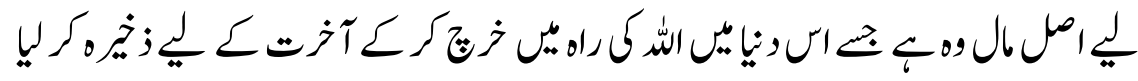

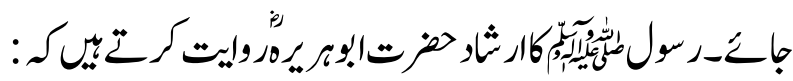


جولأَــ كبمر2019

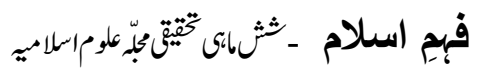

“لو كان لي مثل أحد ذهباً لسرّني أن لاتمر عليّ ثلاث ليال

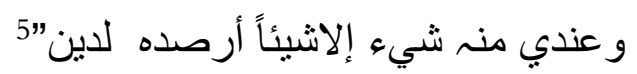

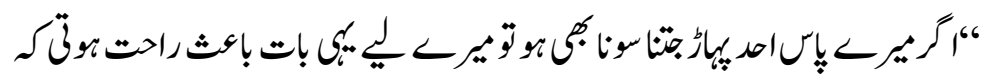

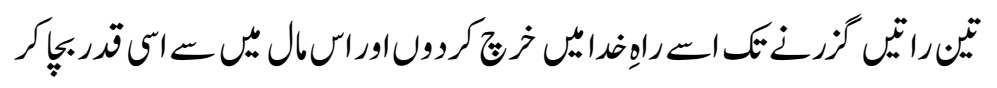

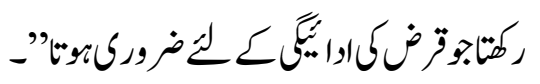

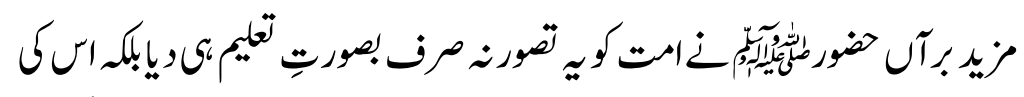

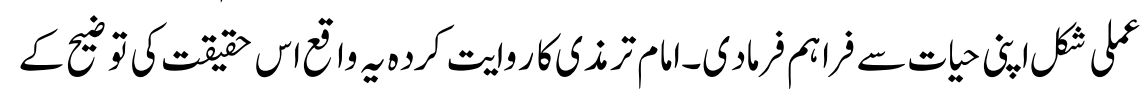

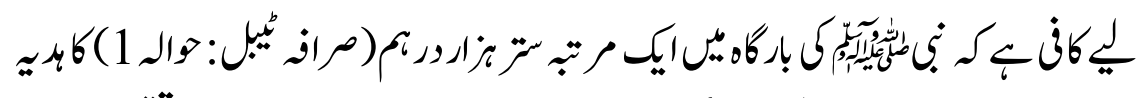

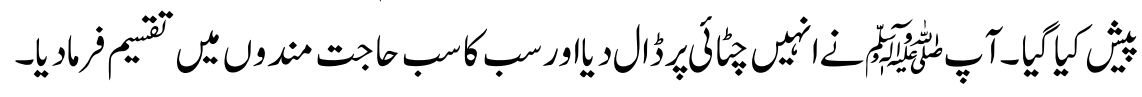

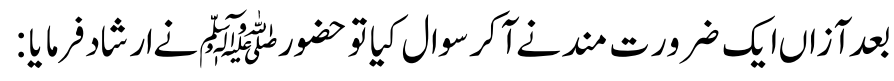

“ما عندي شيء ولكن ابتع عليّ فإذا جاءني شيء قضيتر"

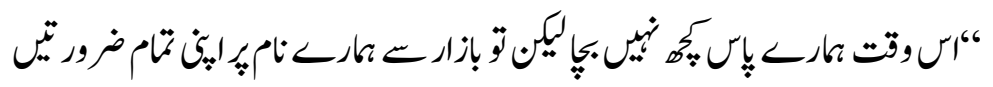

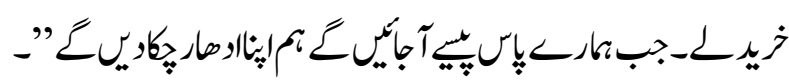

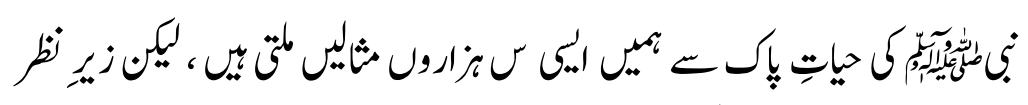

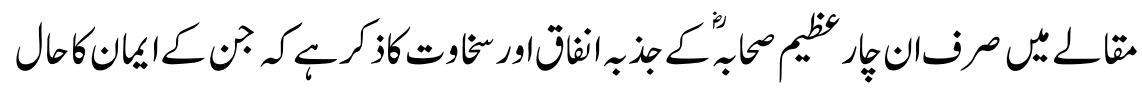

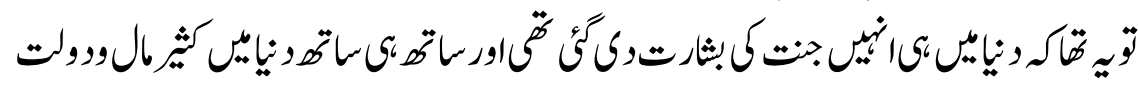

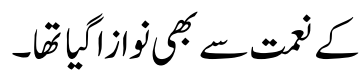

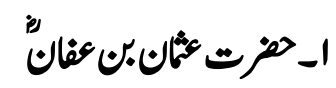

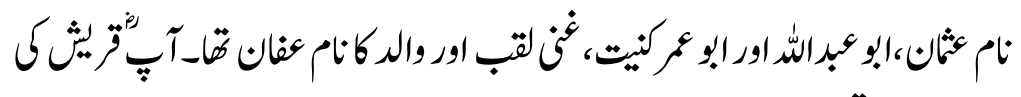

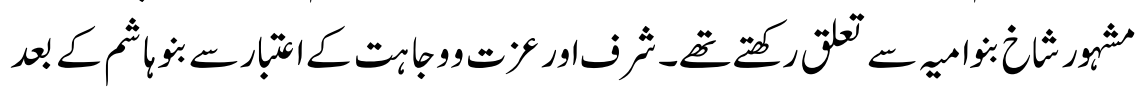

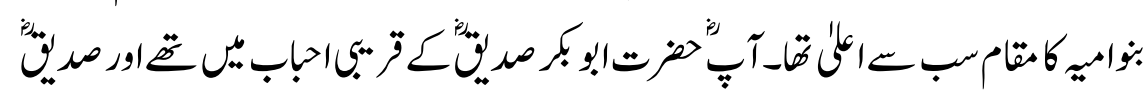

82 


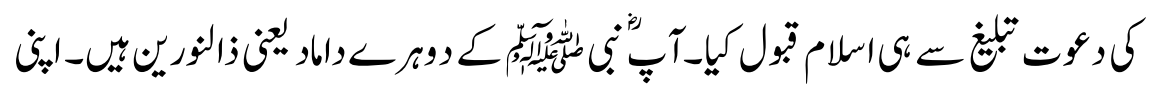

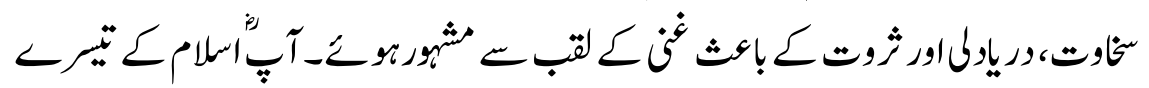

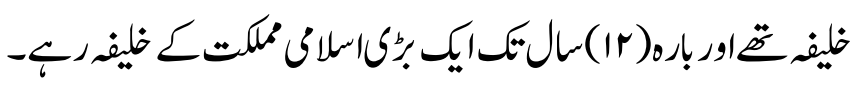

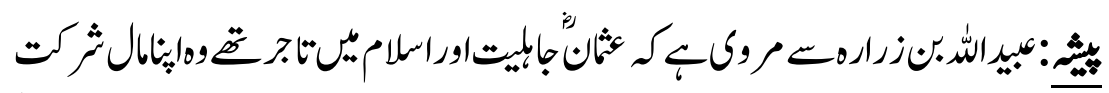

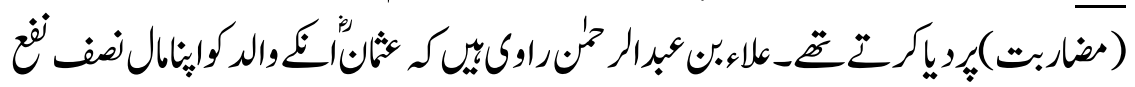

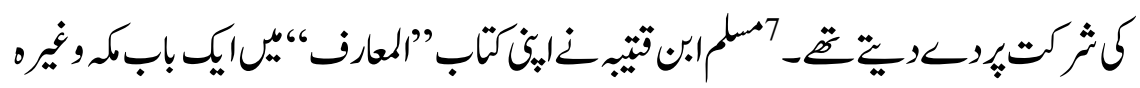

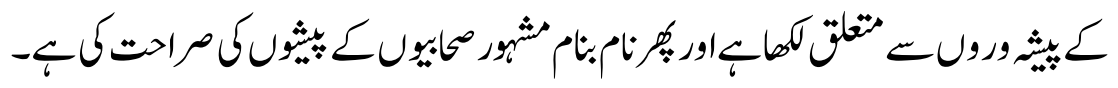

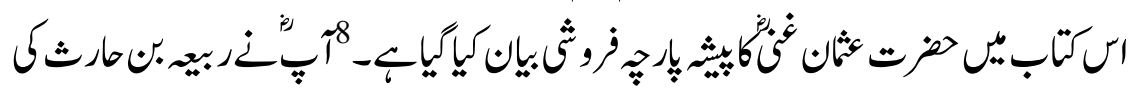

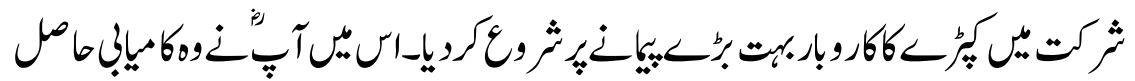

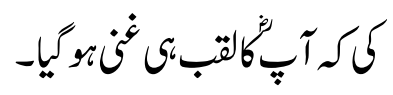

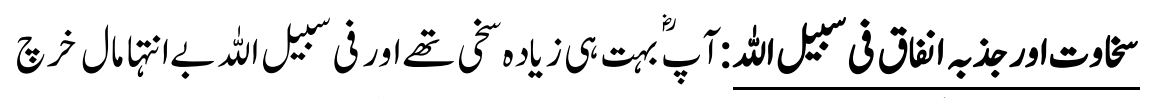

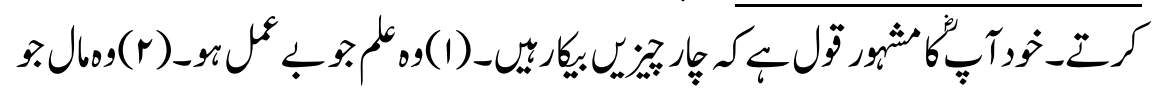

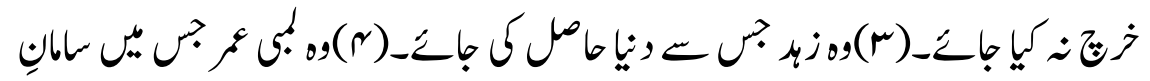

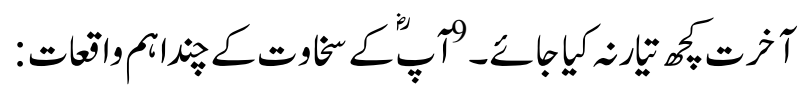

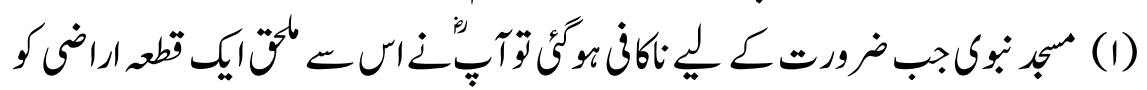

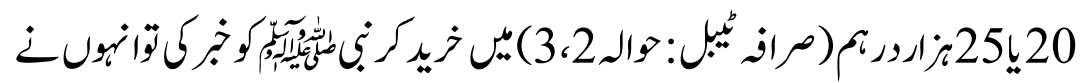

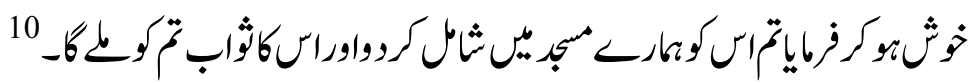

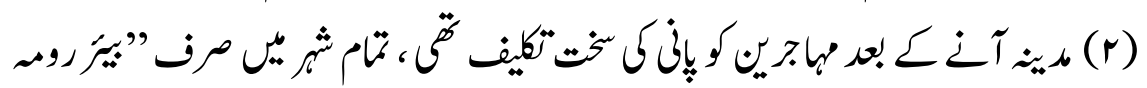

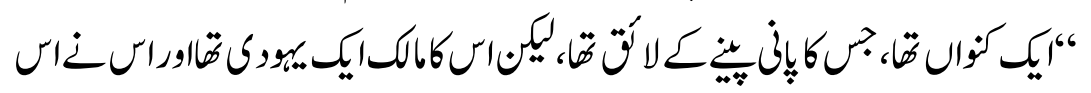

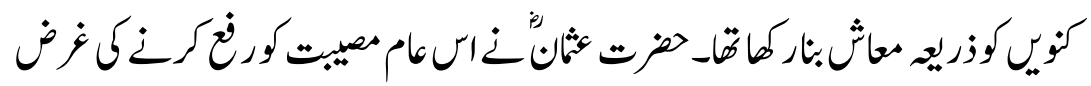

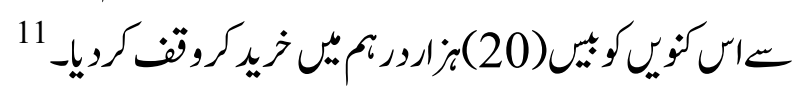




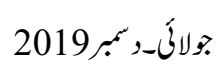

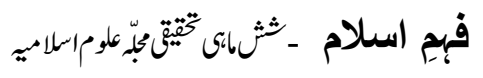

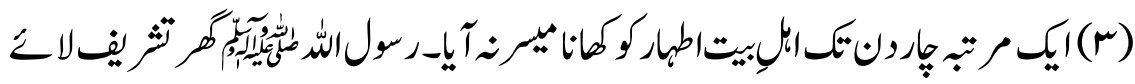

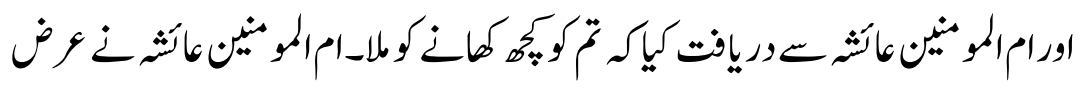

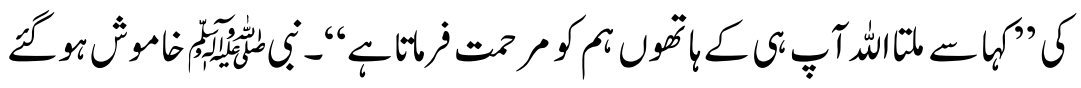

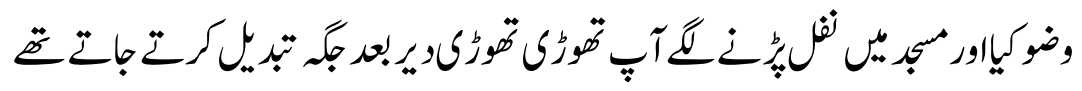

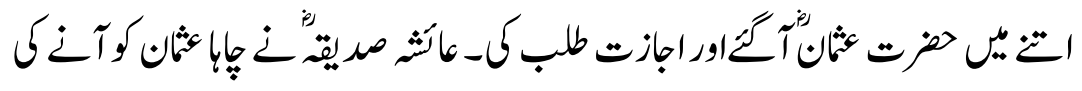

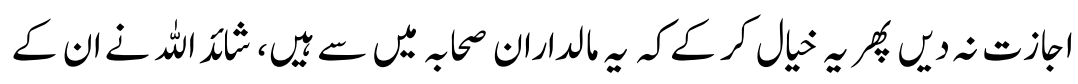

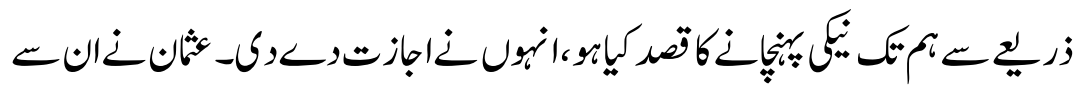

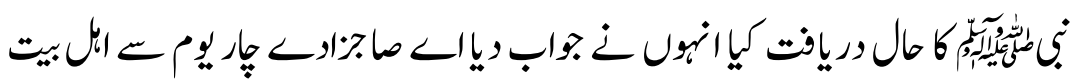

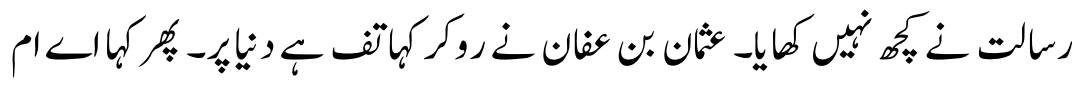

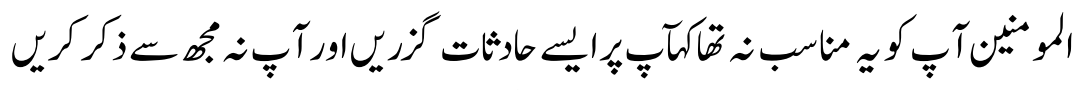

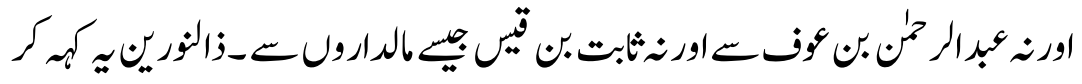

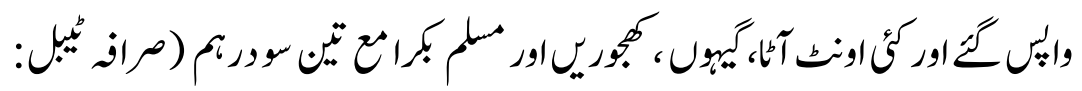

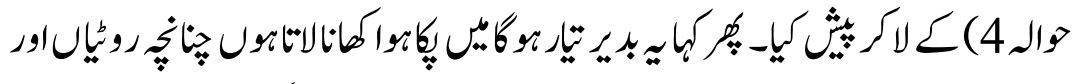

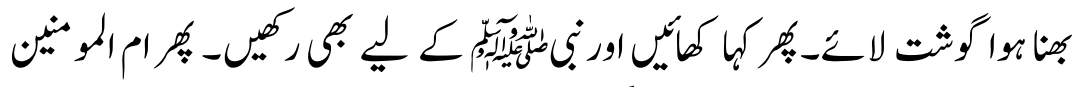

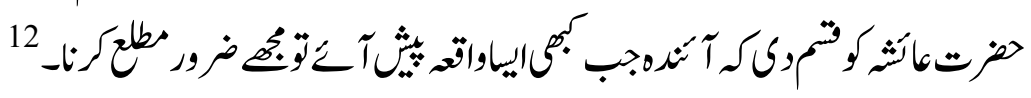

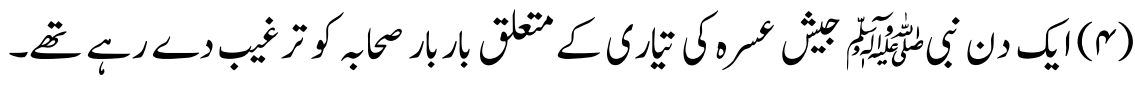

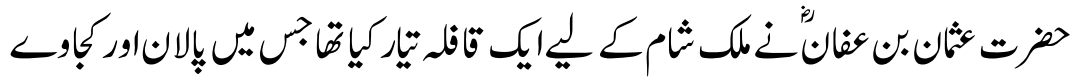

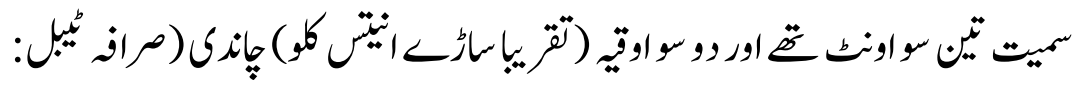

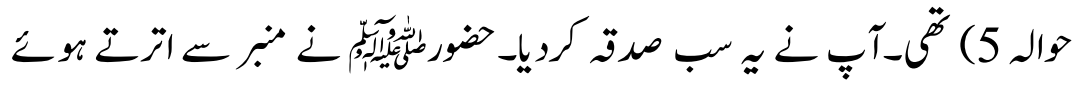

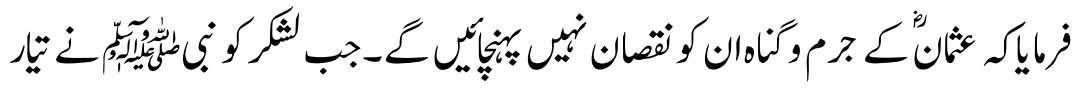

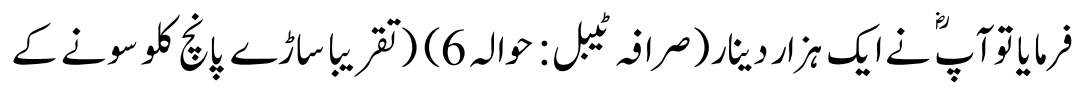

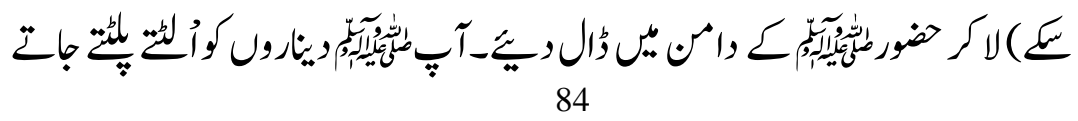


جولأَـــ بمبر2019

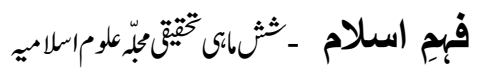

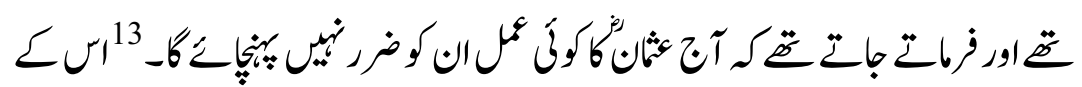

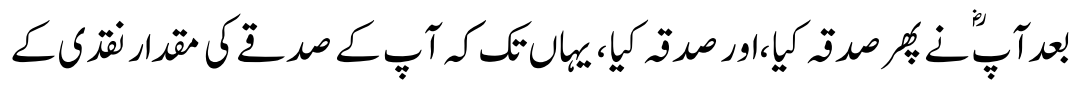

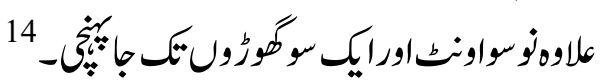

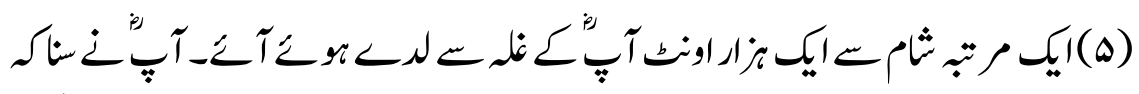

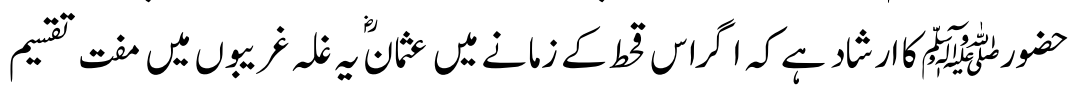

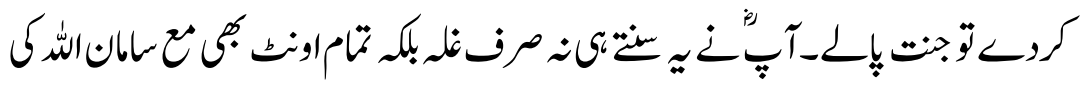

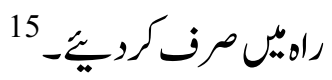

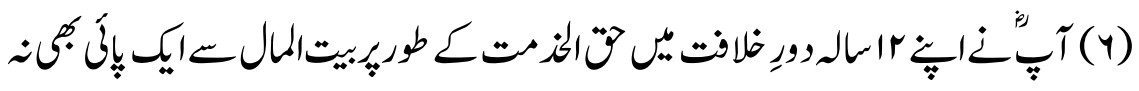

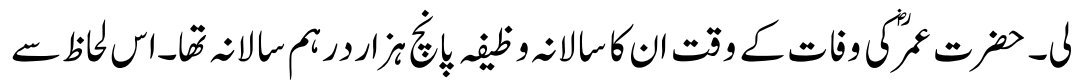

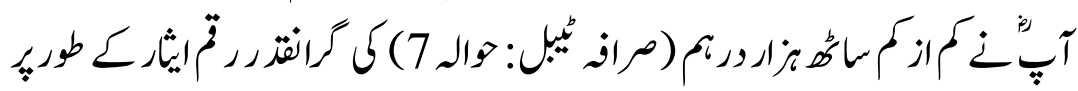

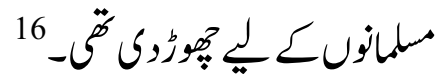

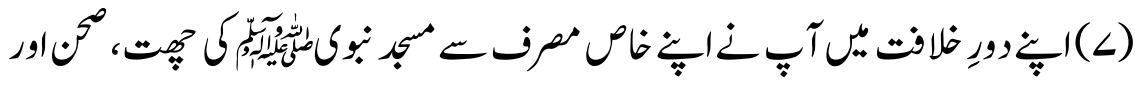

وليوارول كوينت كرايا-

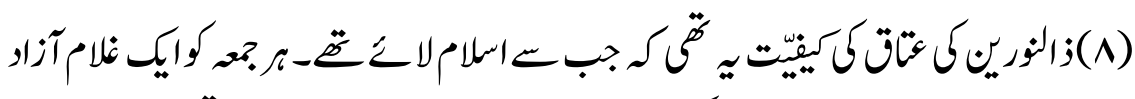

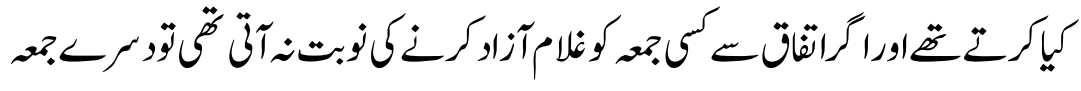

كوروغلام آزاوكروبيّت

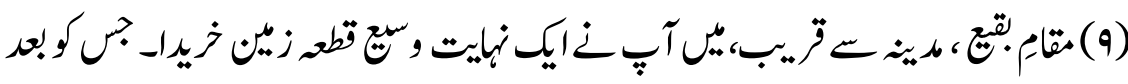

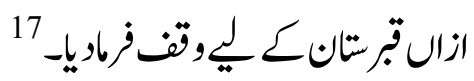

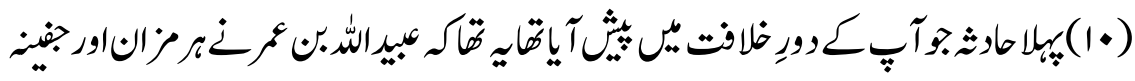

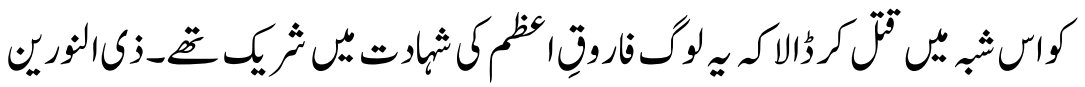

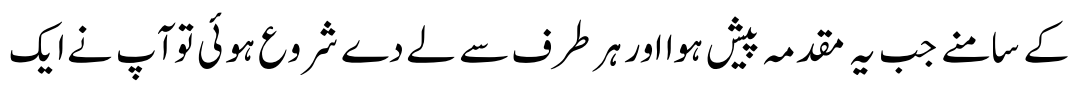

85 


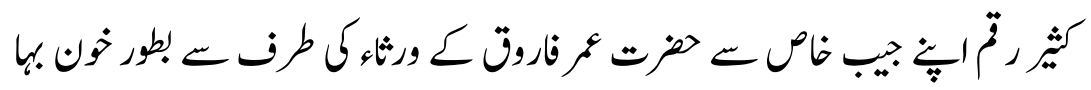

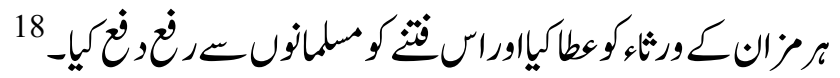

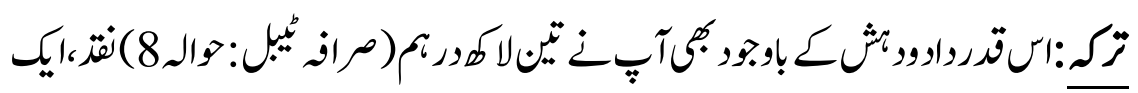

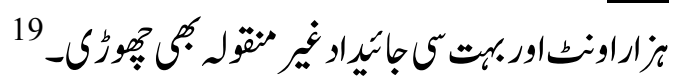

\section{r}

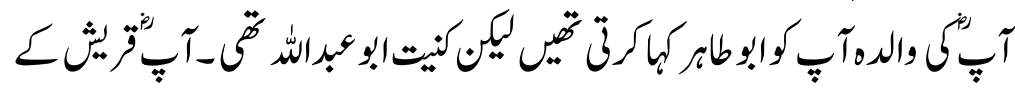

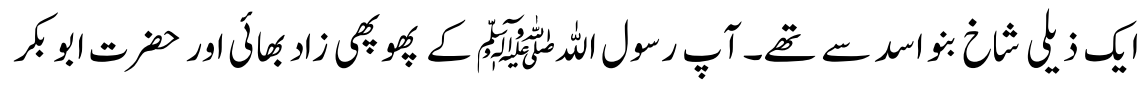

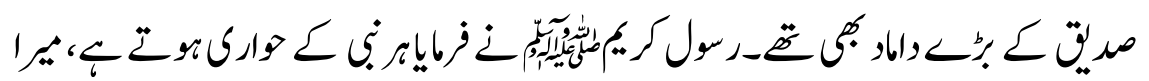

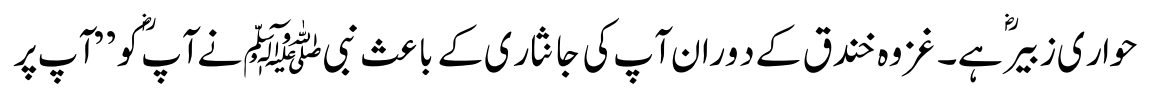

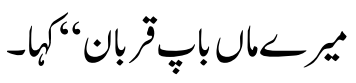

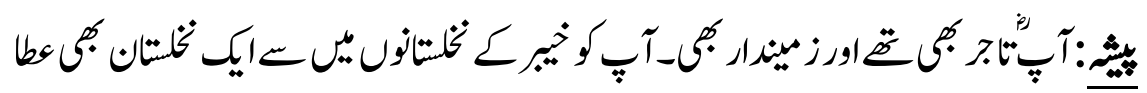

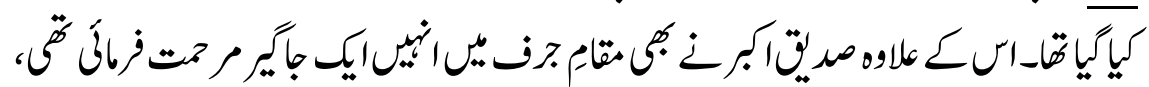

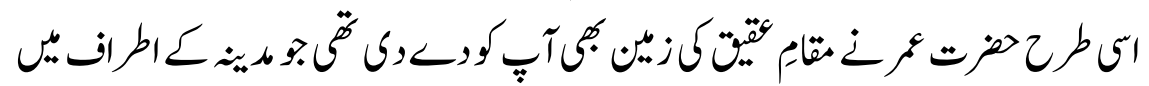

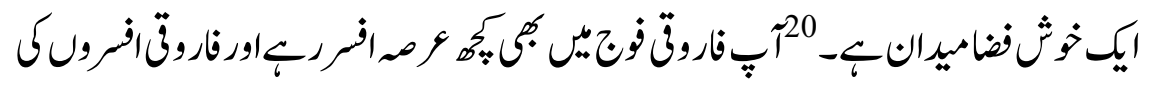

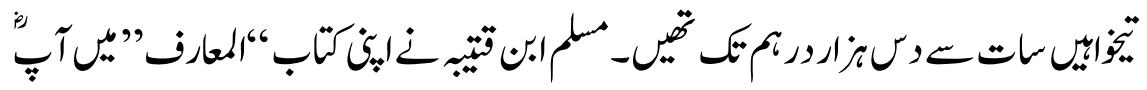

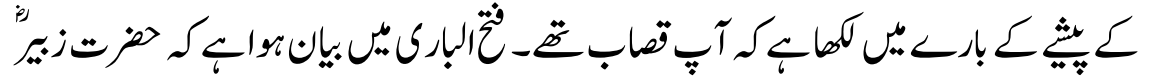

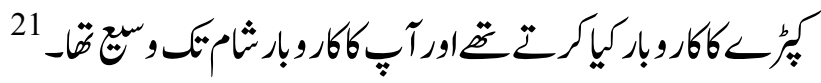

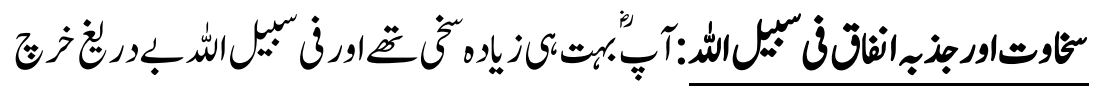

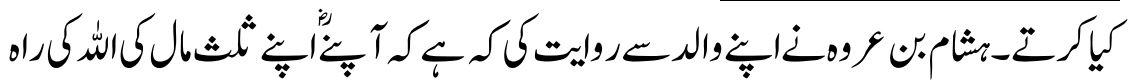

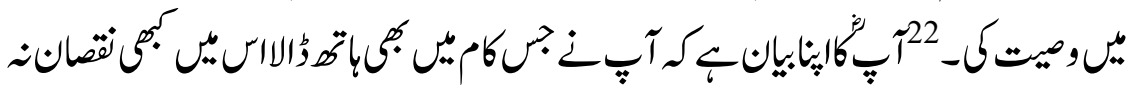

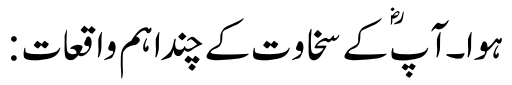


جولأَــ بمبر2019

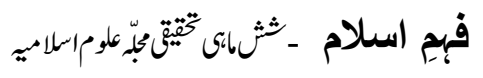

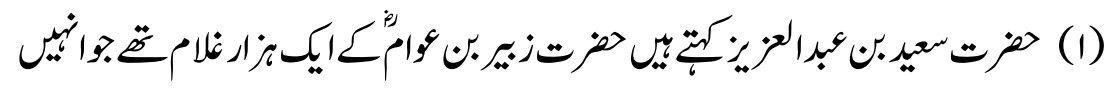

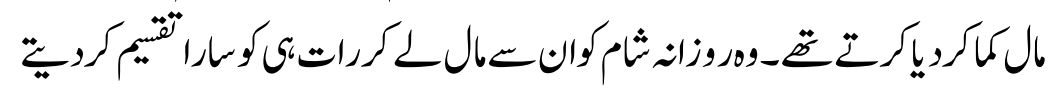

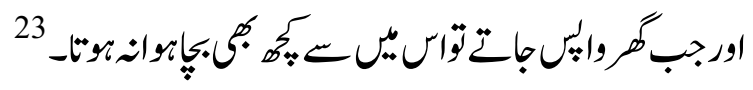

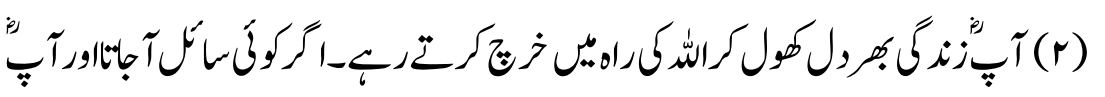

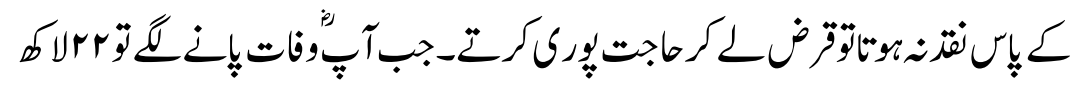

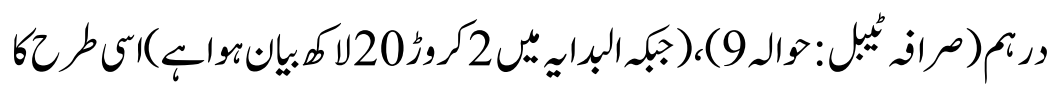

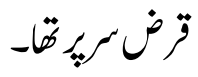

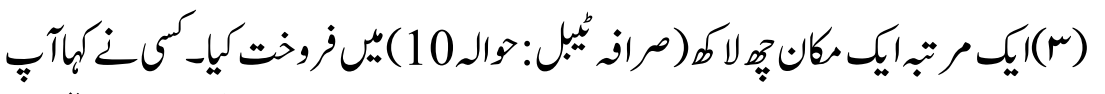

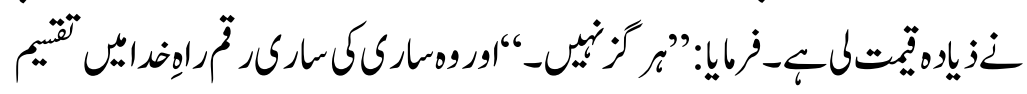

فركا- 24

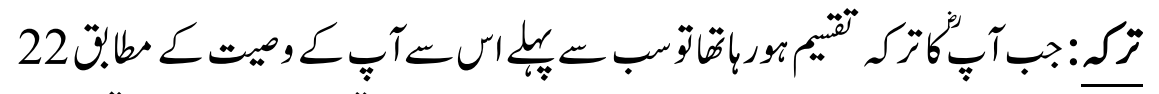

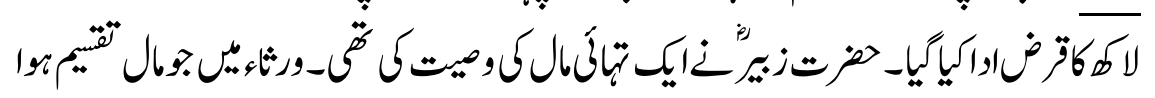

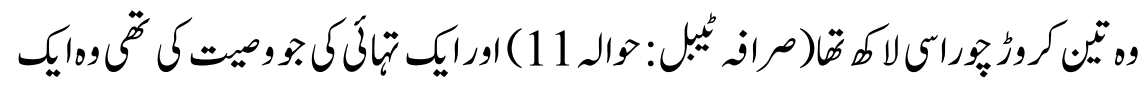

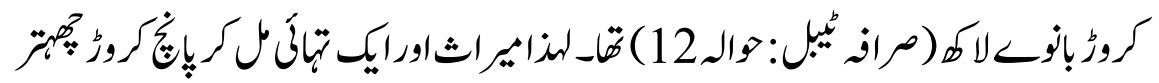

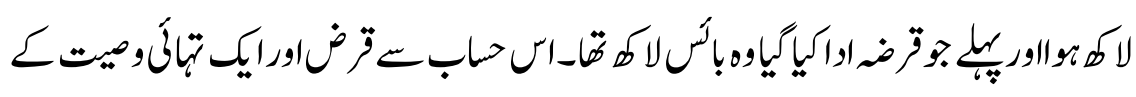

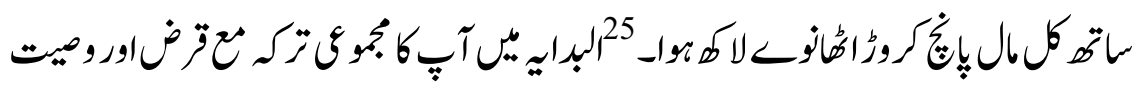

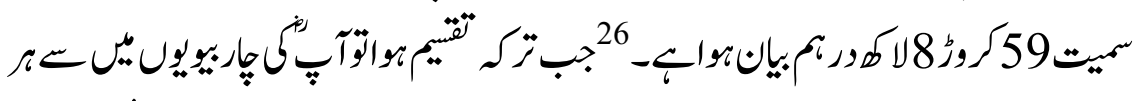

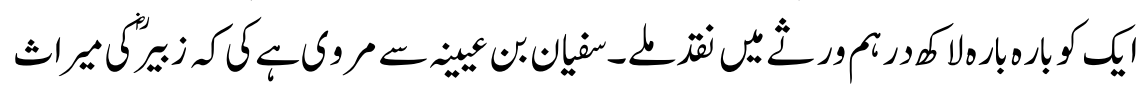

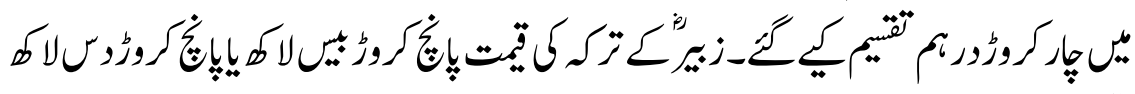

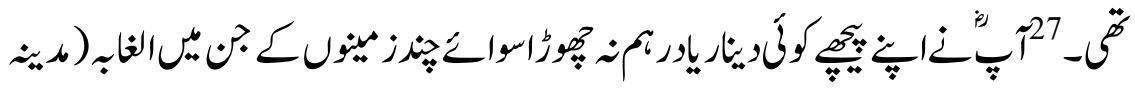

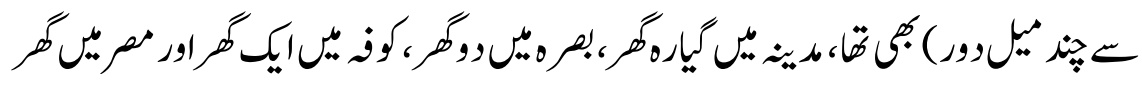

87 


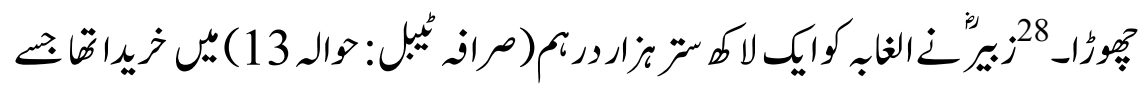

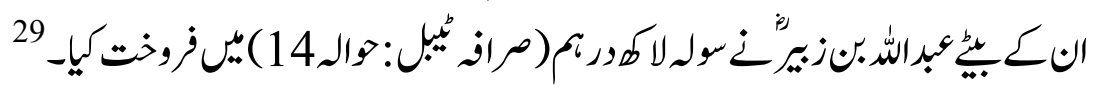

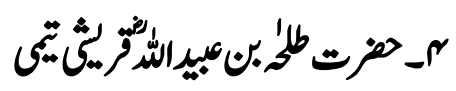

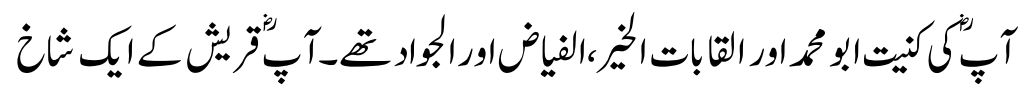

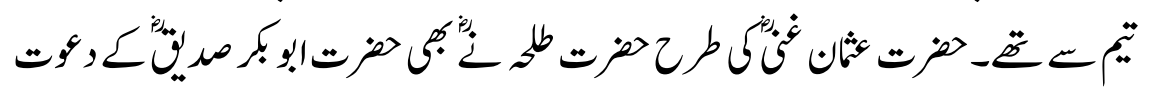

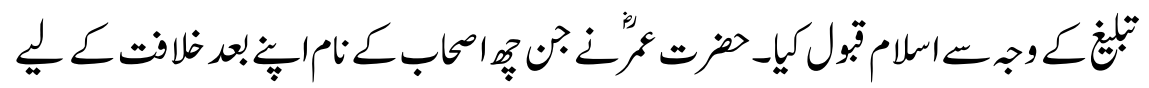

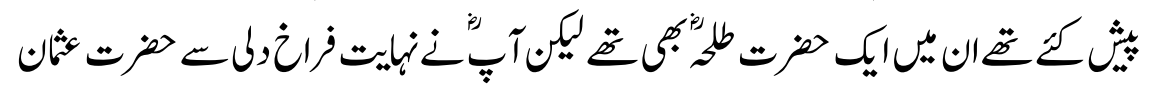

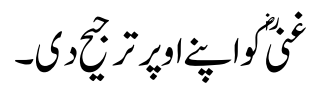

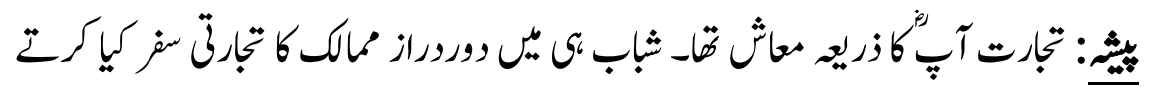

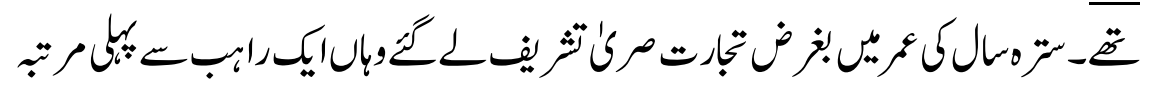

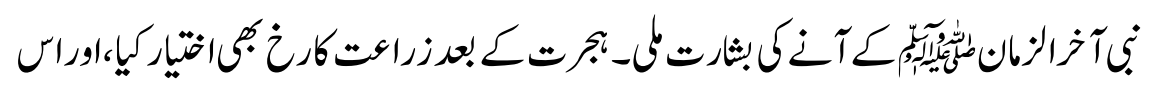

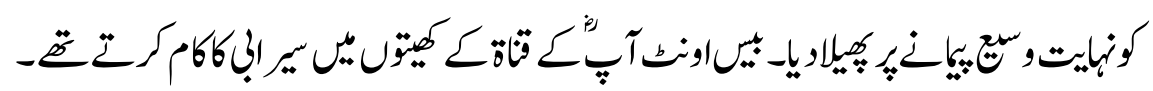

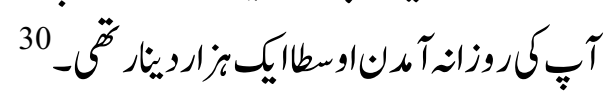

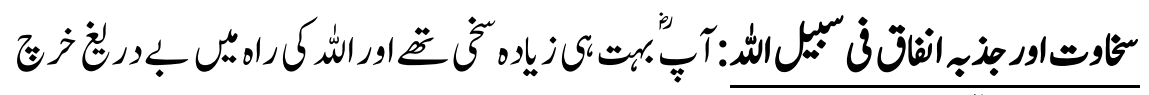

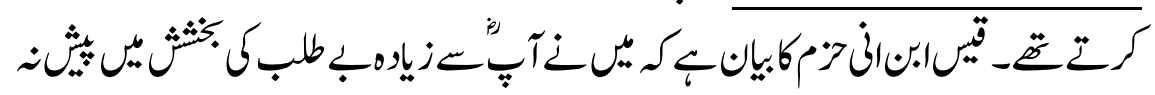

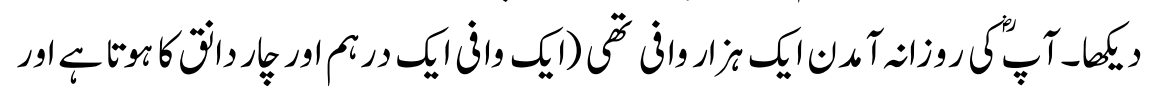

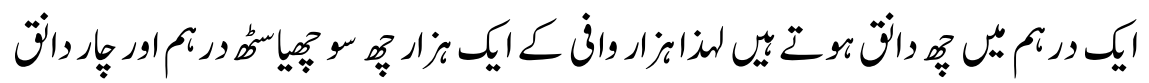

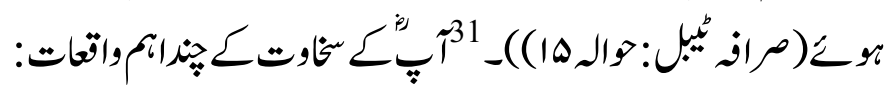

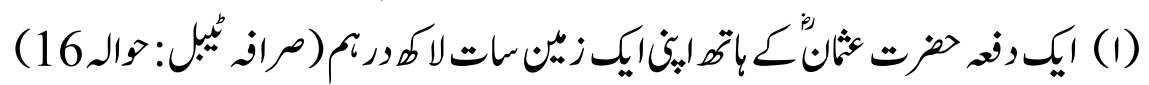

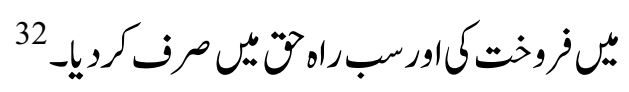


جولأَــ كبر2019

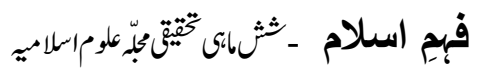

保)

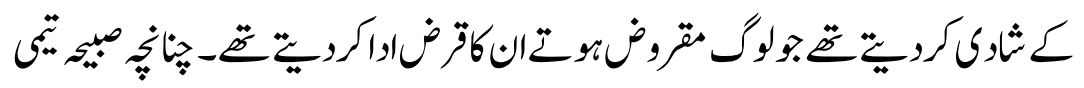

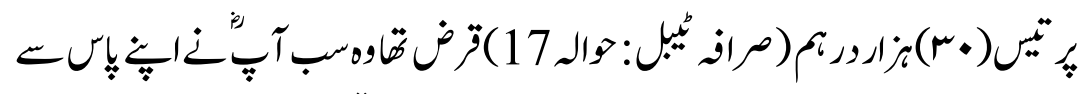

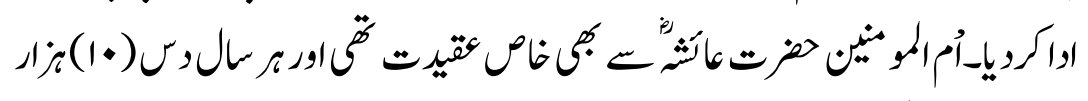

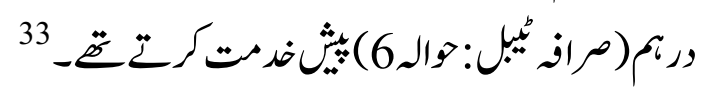

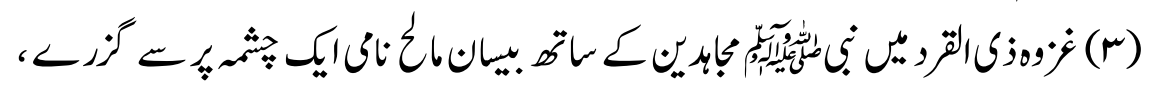

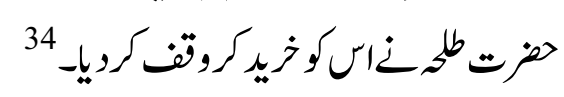

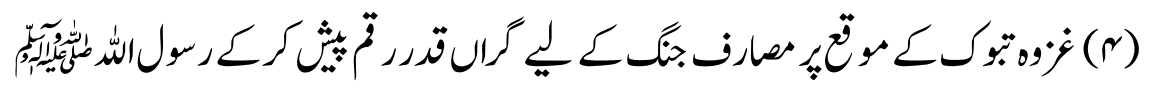

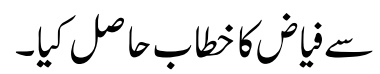

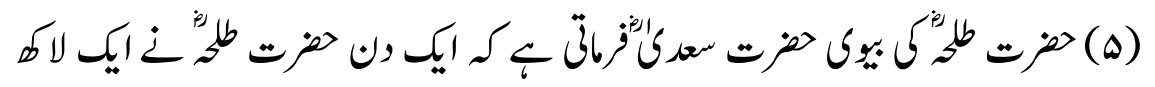

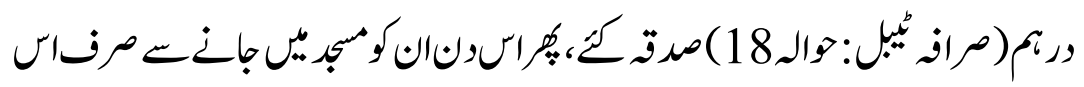

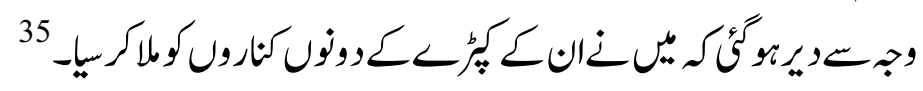

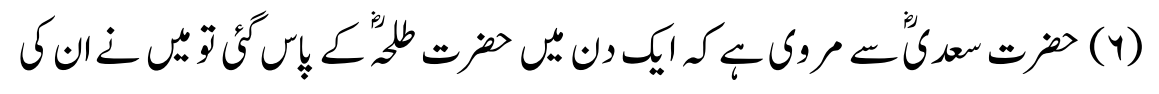

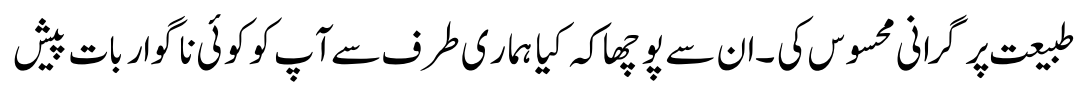

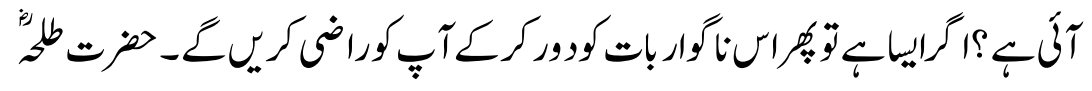

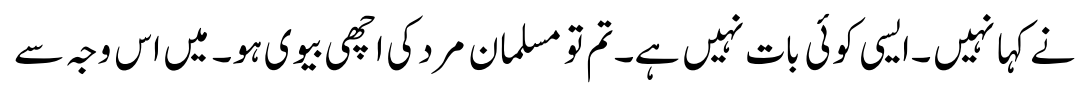

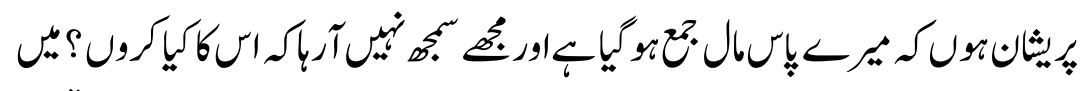

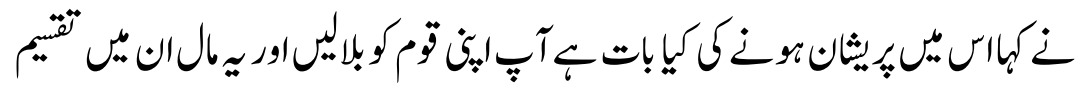

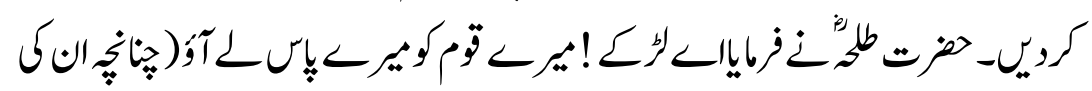

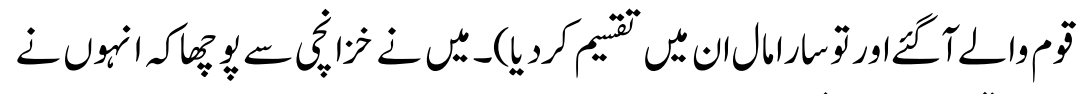

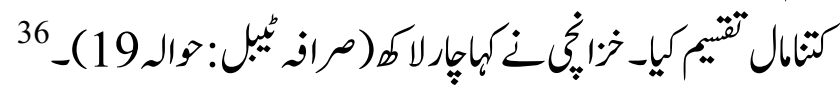

89 


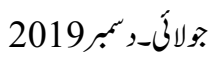

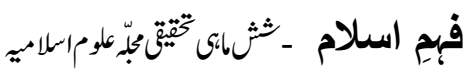

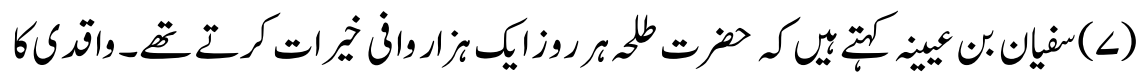

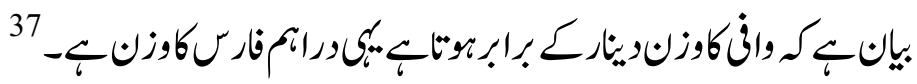

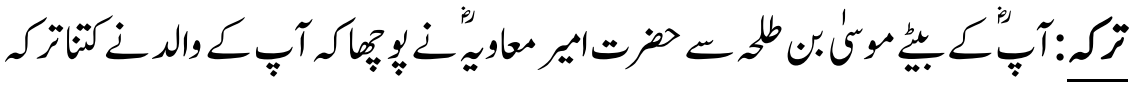

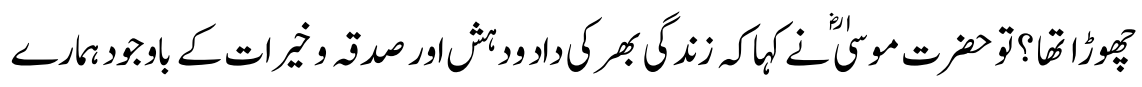

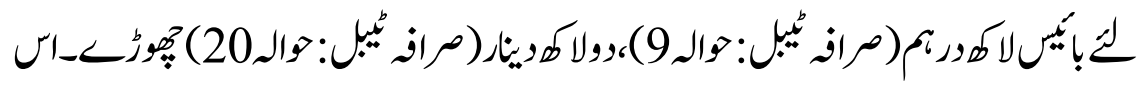

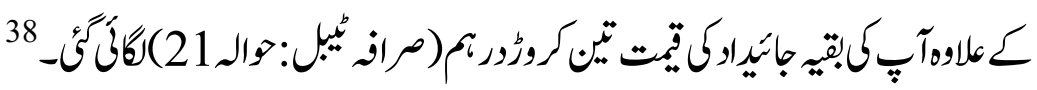

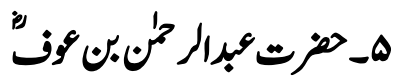

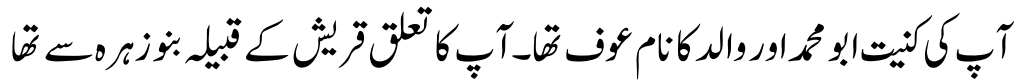

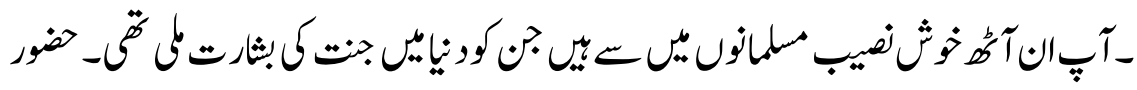

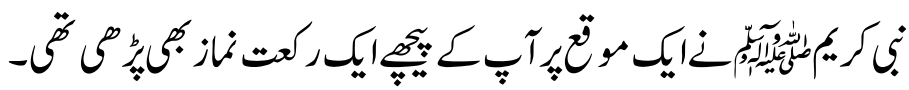

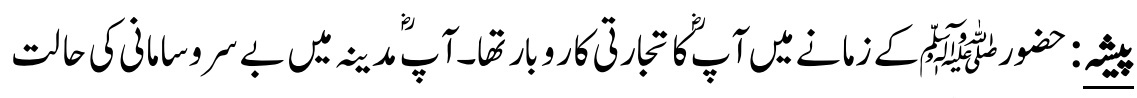

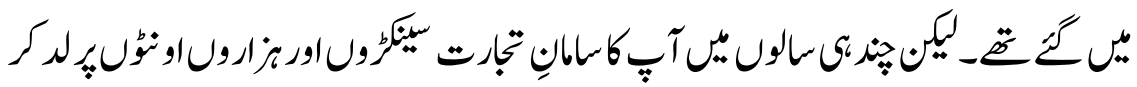

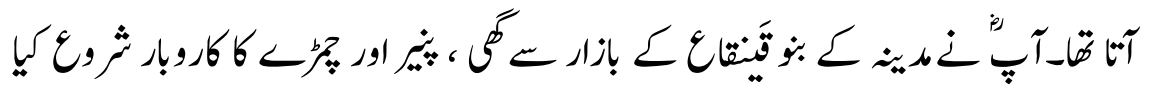

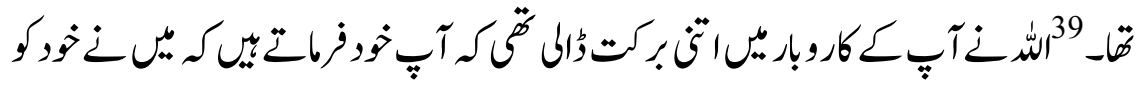

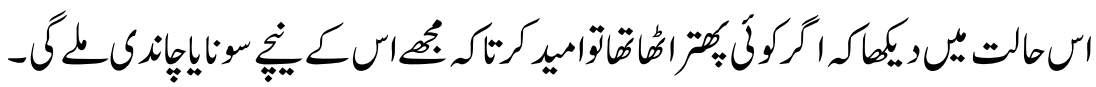

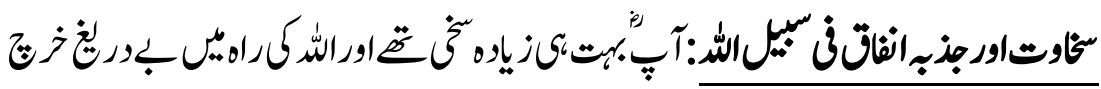

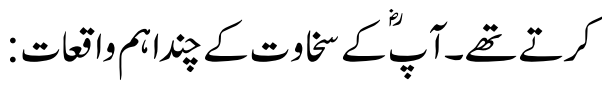

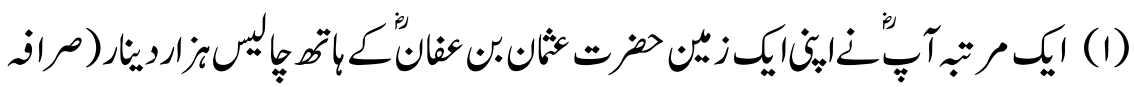

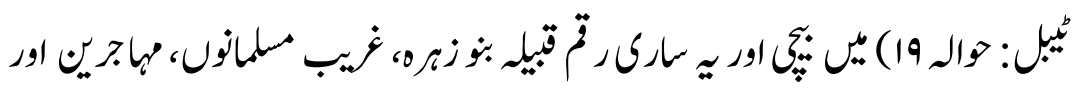

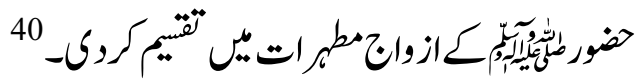

90 


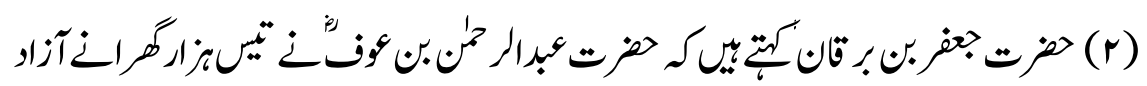

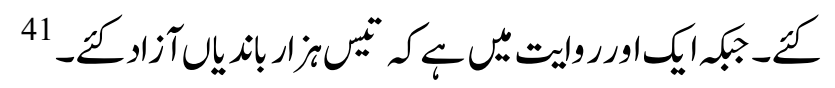

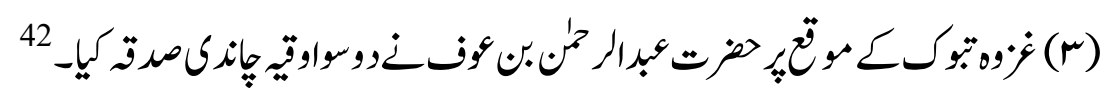

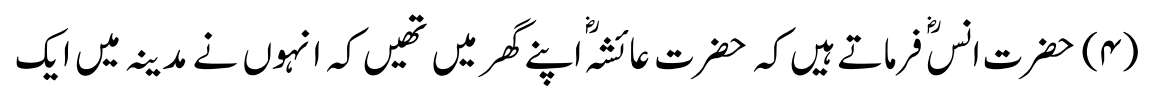

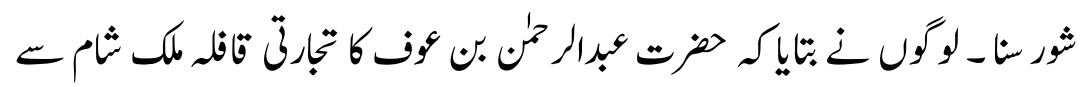

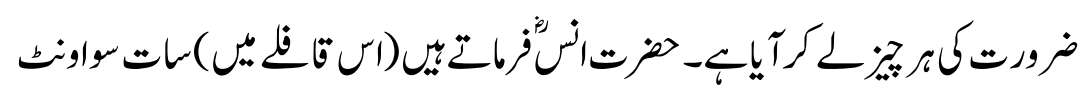

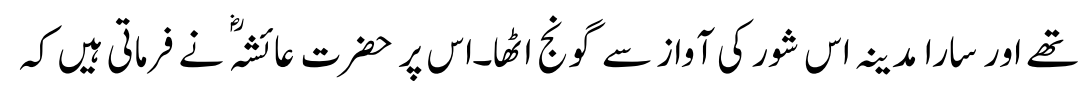

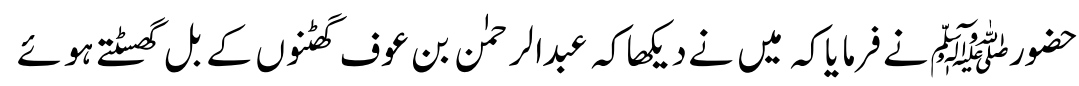

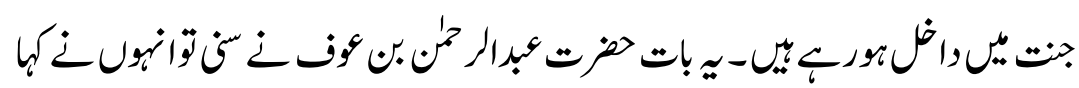

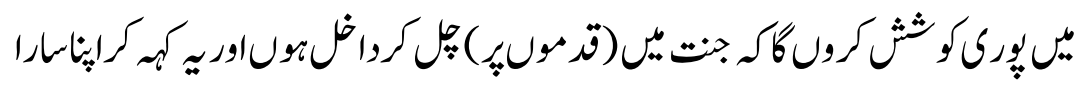

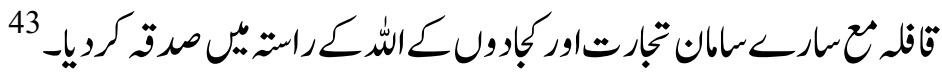

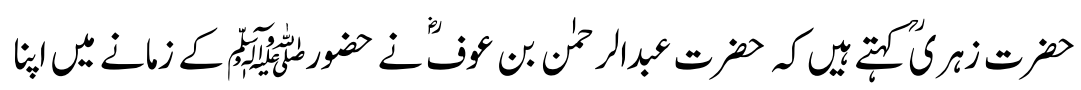

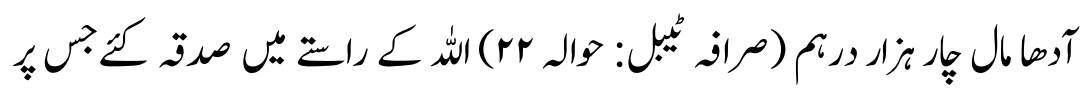

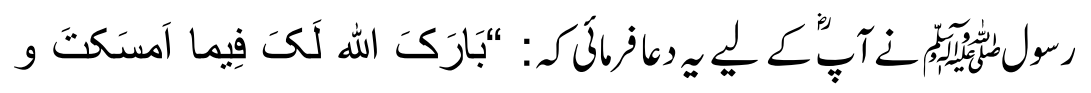

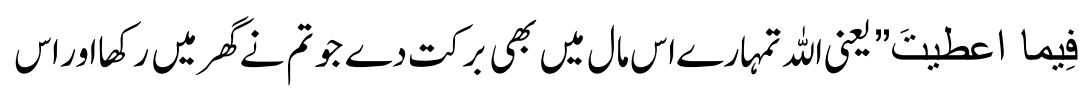

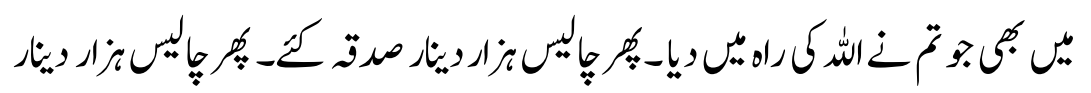

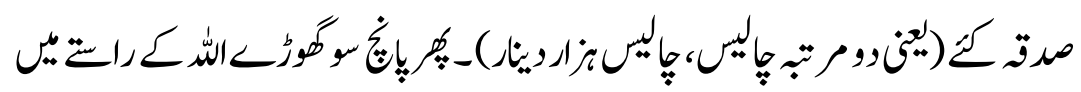

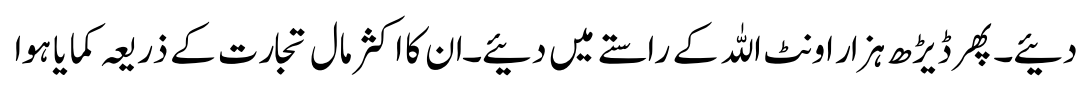


جولأَــ كبر2019

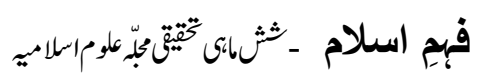

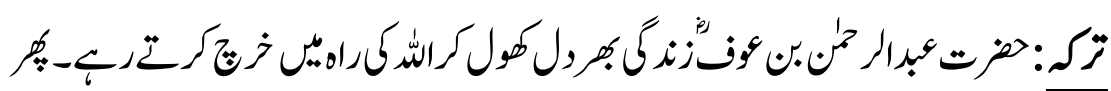

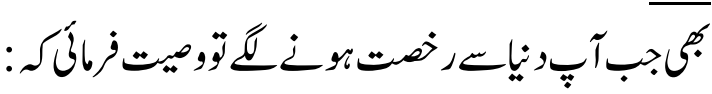

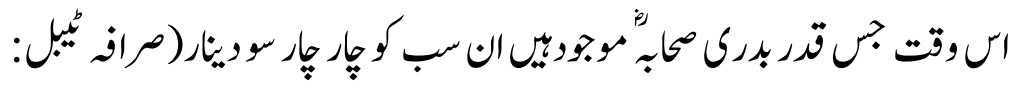

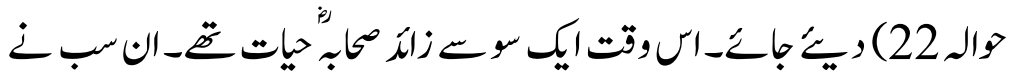

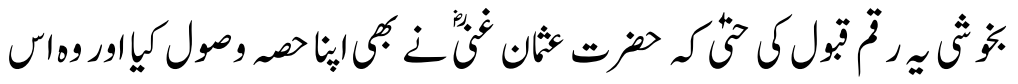

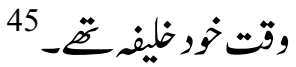

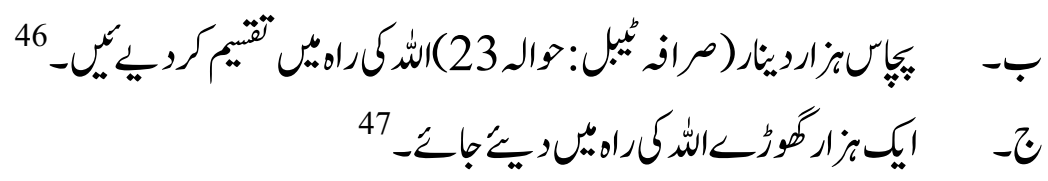

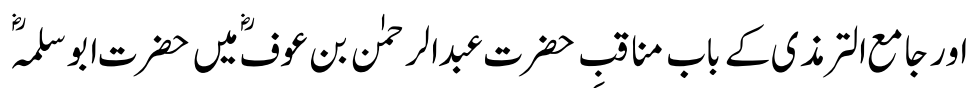

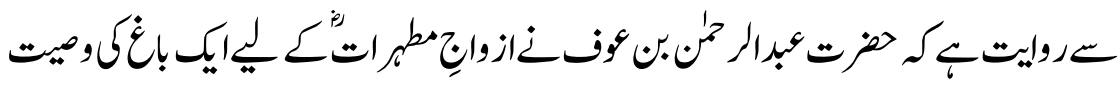

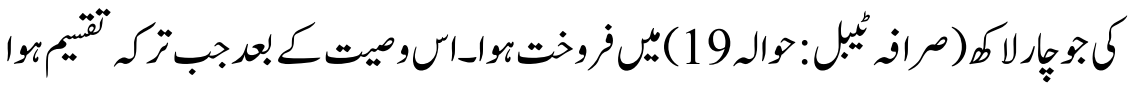

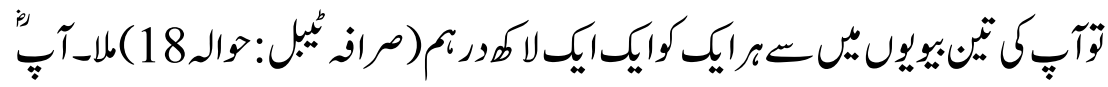

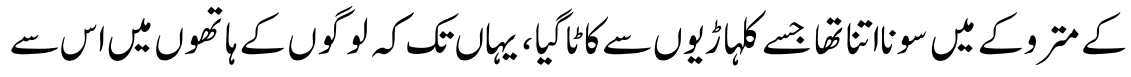

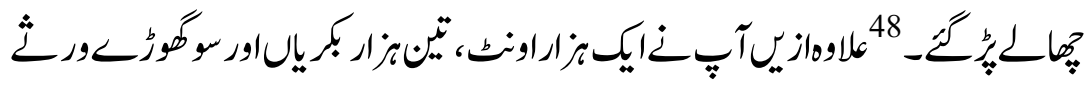

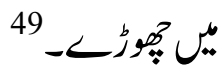

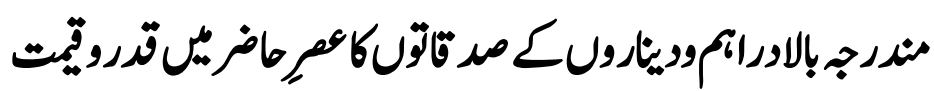

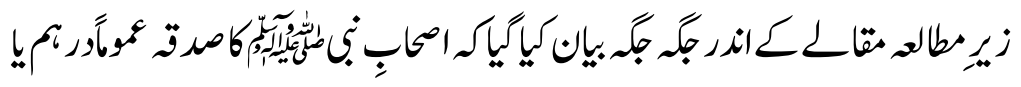

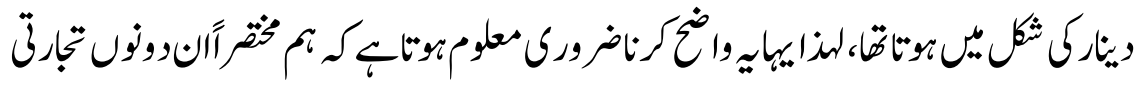

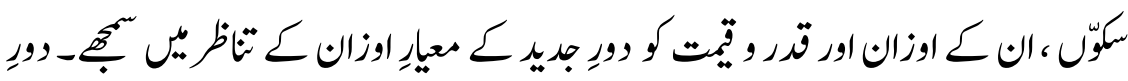

92 


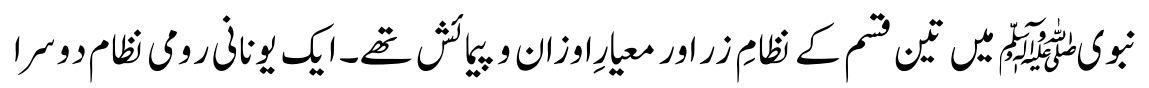

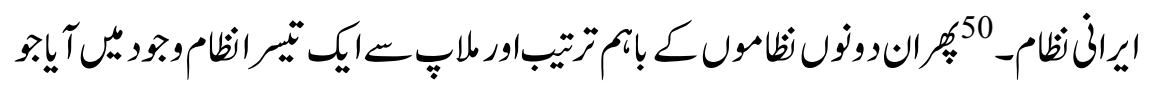

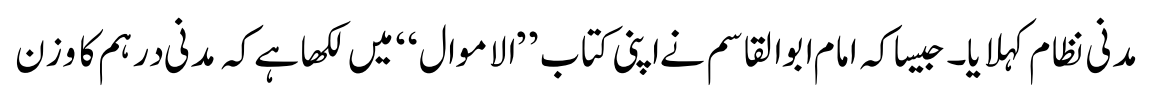

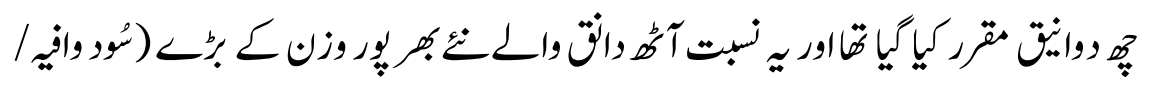

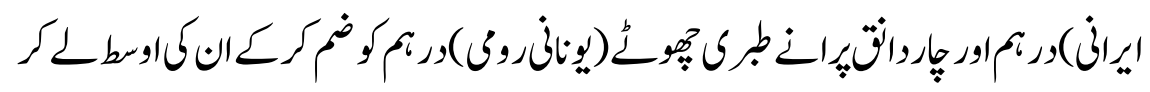

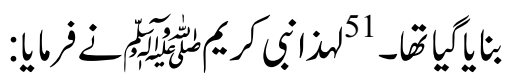

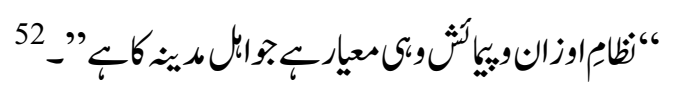

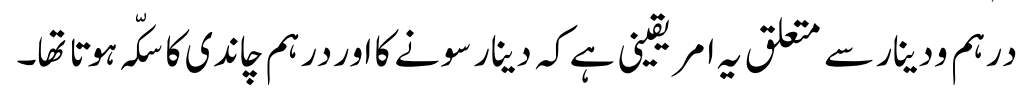

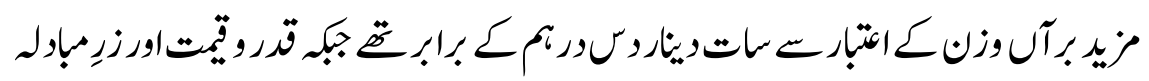

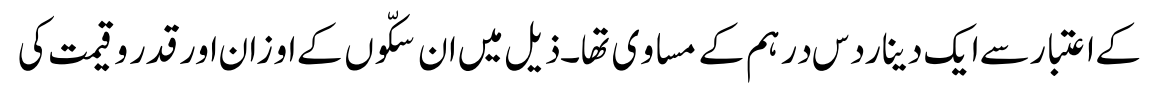

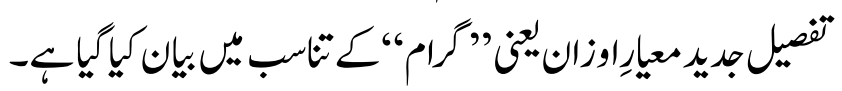

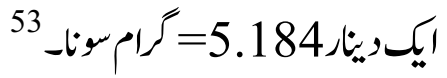

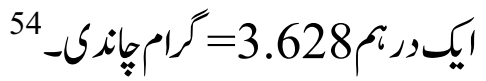

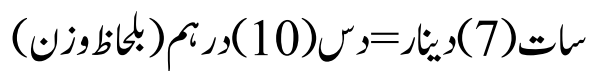$$
\text { 3.628 x 10 } 5.184 \text { × } 7
$$$$
\text { (10) } 36.28
$$

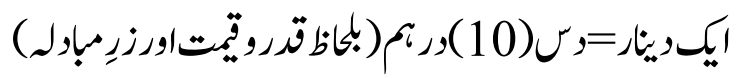

$$
\text { Ұ }=x 3929.4810 \text { 39294.72/- }
$$

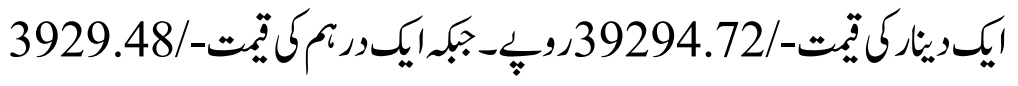

$$
\text { روب }
$$

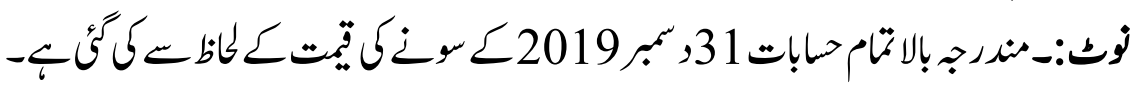

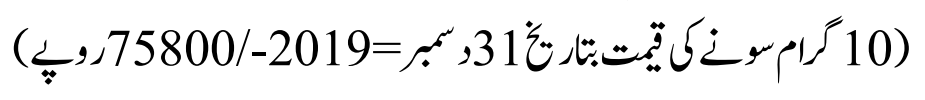




\begin{tabular}{|c|c|c|c|}
\hline 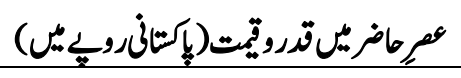 & ورنم & وينار & والـ \\
\hline 39294.72 & 10 & 1 & ت تناسب \\
\hline $1,178,841.60$ & 300 & 30 & 4 \\
\hline $6,562,218.24$ & 1,666 & 167 & 15 \\
\hline $15,717,888.00$ & 4,000 & 400 & 22 \\
\hline $31,985,902.08$ & 8,142 & 8,14 & 5 \\
\hline $39,294,720.00$ & 10,000 & 1,000 & 6 \\
\hline $78,589,440.00$ & 20,000 & 2,000 & 2 \\
\hline $98,236,800.00$ & 25,000 & 2,500 & 3 \\
\hline $117,884,160.00$ & 30,000 & 3,000 & 17 \\
\hline $235,768,320.00$ & 60,000 & 6,000 & 7 \\
\hline $275,063,040.00$ & 70,000 & 7,000 & 1 \\
\hline $392,947,200.00$ & 100,000 & 10,000 & 18 \\
\hline $668,010,240.00$ & 170,000 & 17,000 & 13 \\
\hline $1,178,841,600.00$ & 300,000 & 30,000 & 8 \\
\hline $1,571,788,800.00$ & 400,000 & 40,000 & 19 \\
\hline $1,964,736,000.00$ & 500,000 & 50,000 & 23 \\
\hline $2,357,683,200.00$ & 600,000 & 60,000 & 10 \\
\hline $2,750,630,400.00$ & 700,000 & 70,000 & 16 \\
\hline $6,287,155,200.00$ & $1,600,000$ & 160,000 & 14 \\
\hline $7,858,944,000.00$ & $2,000,000$ & 200,000 & 20 \\
\hline $8,653,561,827.84$ & $2,200,000$ & 220,000 & 9 \\
\hline $75,445,862,400.00$ & $19,200,000$ & $1,920,000$ & 12 \\
\hline $117,884,160,000.00$ & $30,000,000$ & $3,000,000$ & 21 \\
\hline $150,891,724,800.00$ & $38,400,000$ & $3,840,000$ & 11 \\
\hline
\end{tabular}




\section{ثلام.كث}

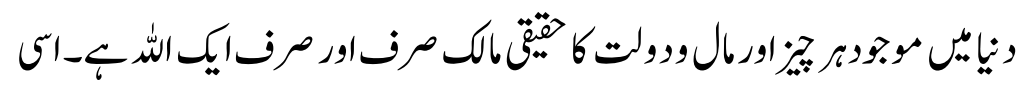

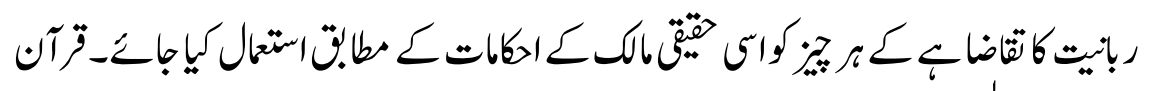

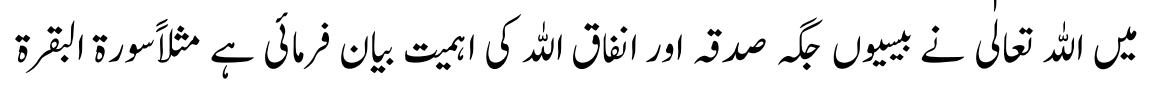
每

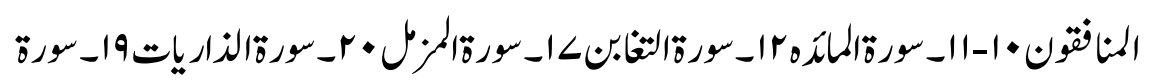

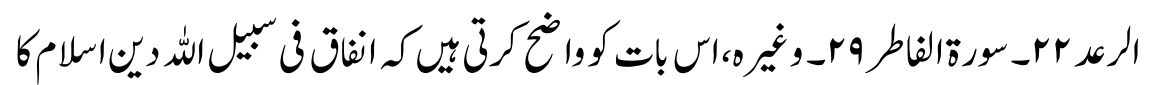

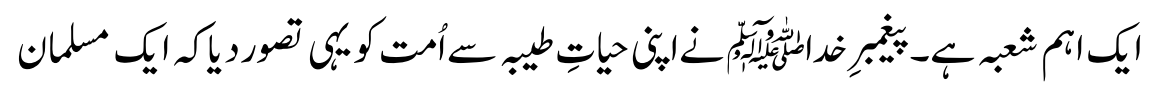

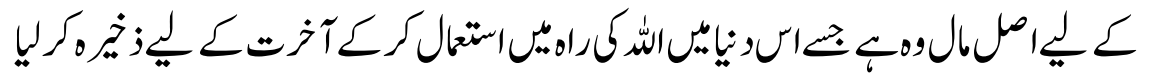

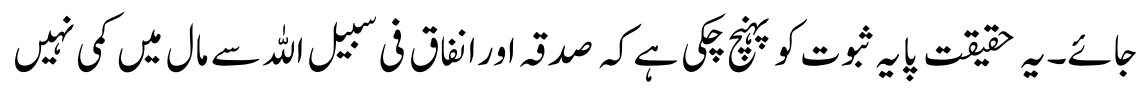

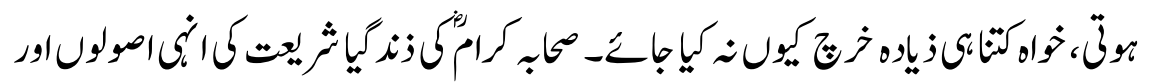

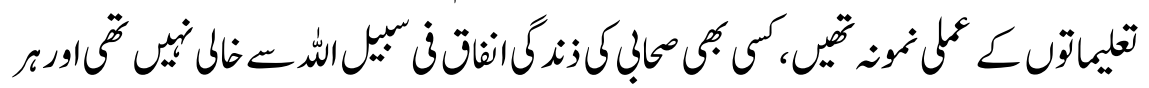

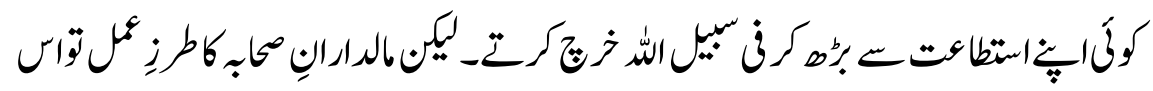

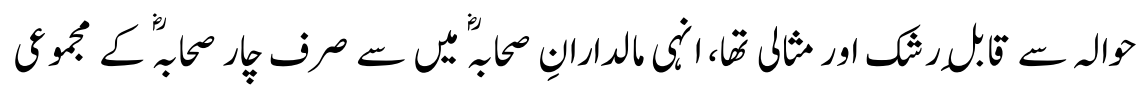

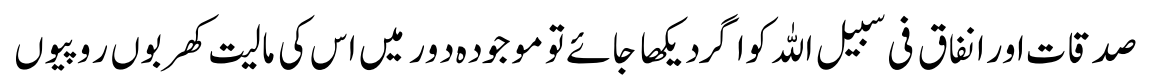

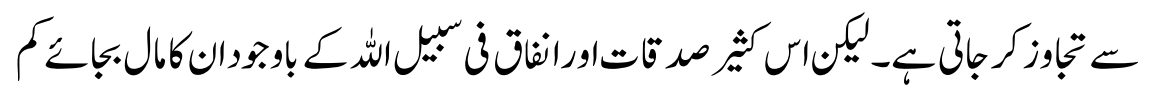

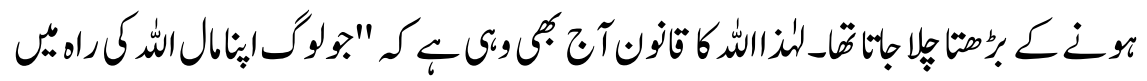

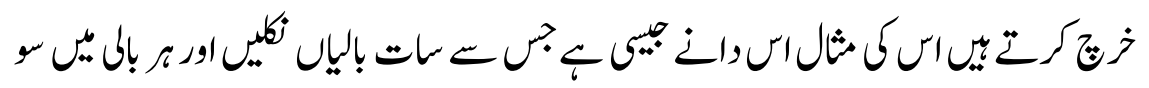

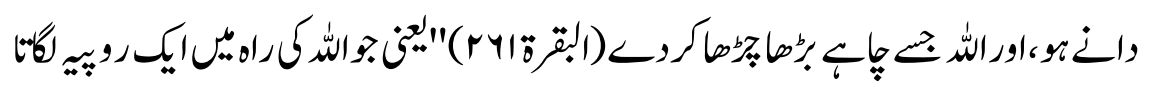

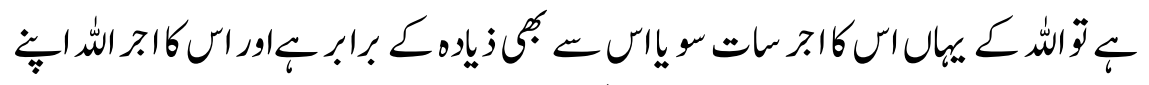

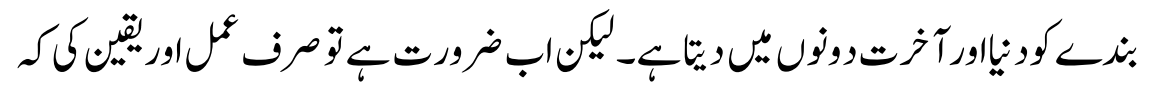




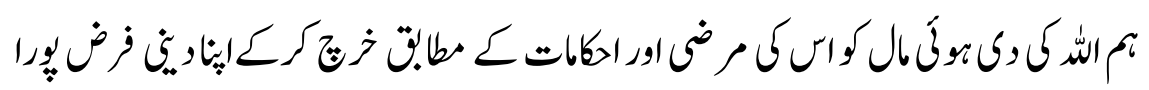

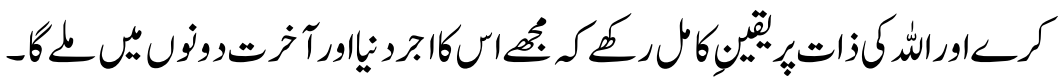

\section{حواثىو هوالـجات}

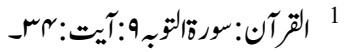

$$
\begin{aligned}
& 22
\end{aligned}
$$

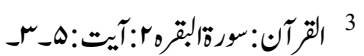

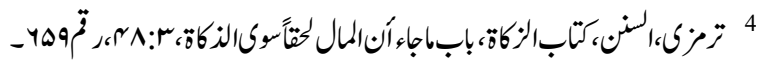

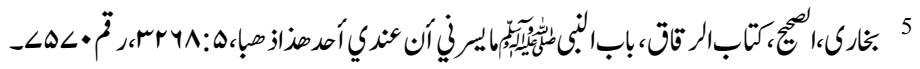

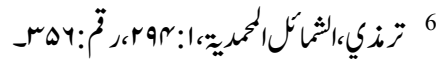

$$
\begin{aligned}
& 7 \\
& 8
\end{aligned}
$$

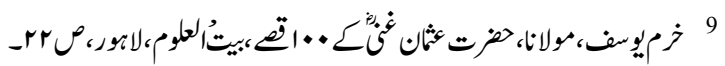

$$
\begin{aligned}
& 10
\end{aligned}
$$

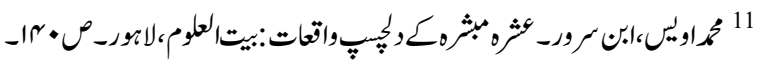

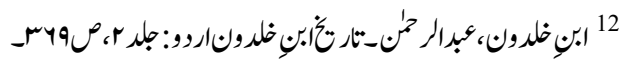

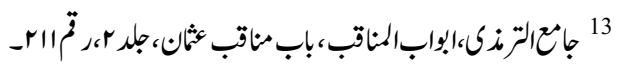

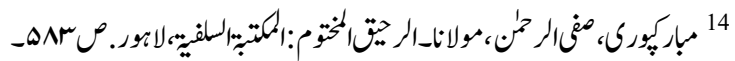

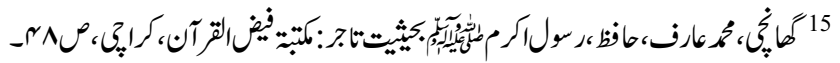

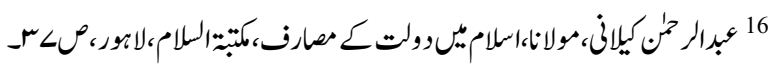

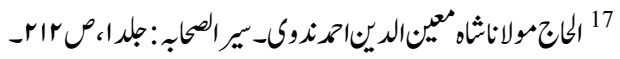

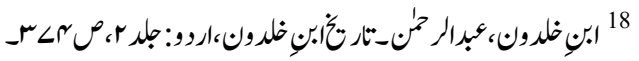

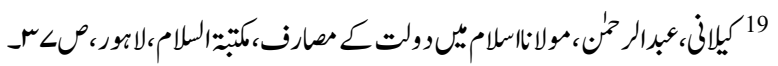

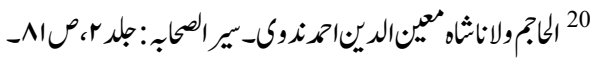

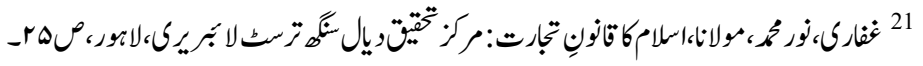

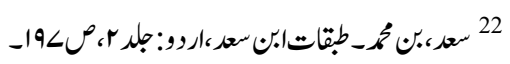

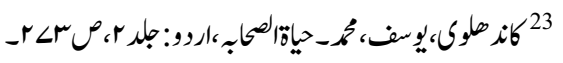




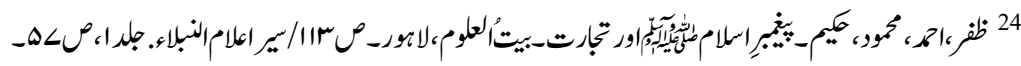

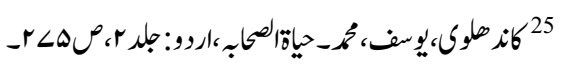

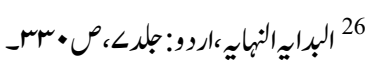

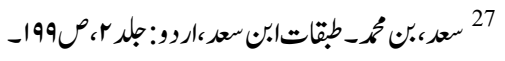

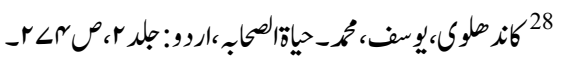

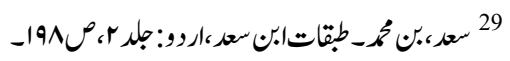

30 30

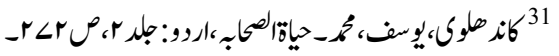

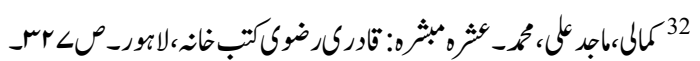

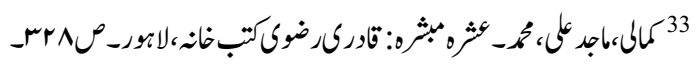

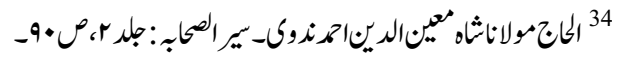

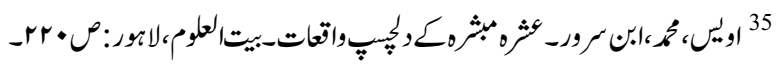

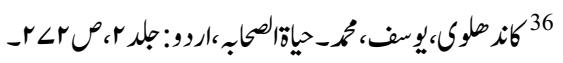

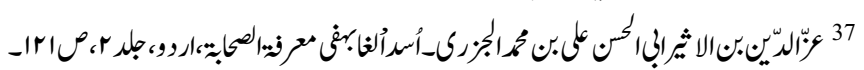

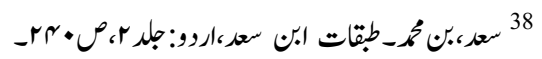

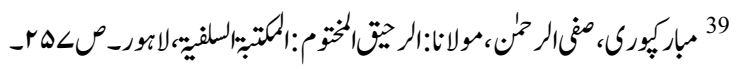

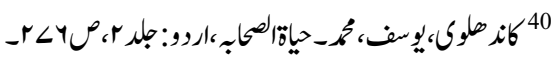
41

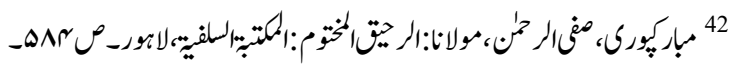

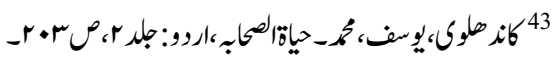
44

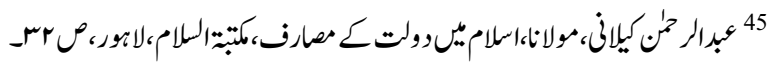

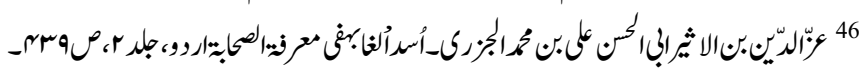

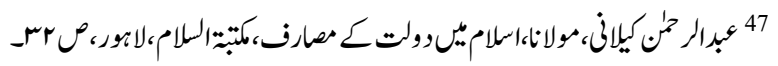

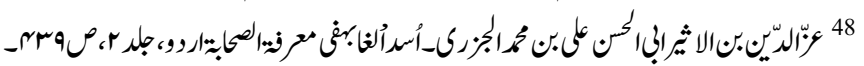

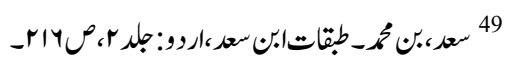

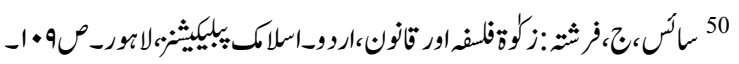




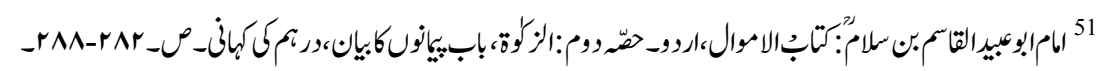

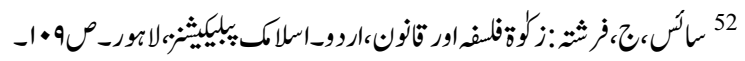

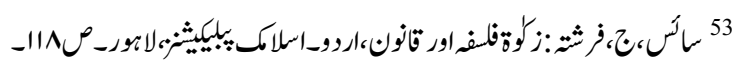
54 